\title{
Efficient Isotope Recovery and Seamless Recycle of Target Material in a Salt Matrix
}

David F. Williams

Susan L. Hogle

Guillermo D. DelCul

September 2019 


\title{
DOCUMENT AVAILABILITY
}

Reports produced after January 1, 1996, are generally available free via US Department of Energy (DOE) SciTech Connect.

Website www.osti.gov

Reports produced before January 1, 1996, may be purchased by members of the public from the following source:

\author{
National Technical Information Service \\ 5285 Port Royal Road \\ Springfield, VA 22161 \\ Telephone 703-605-6000 (1-800-553-6847) \\ TDD 703-487-4639 \\ Fax 703-605-6900 \\ E-mail info@ntis.gov \\ Website http://classic.ntis.gov/
}

Reports are available to DOE employees, DOE contractors, Energy Technology Data Exchange representatives, and International Nuclear Information System representatives from the following source:

Office of Scientific and Technical Information

PO Box 62

Oak Ridge, TN 37831

Telephone 865-576-8401

Fax 865-576-5728

E-mail reports@osti.gov

Website http://www.osti.gov/contact.html

This report was prepared as an account of work sponsored by an agency of the United States Government. Neither the United States Government nor any agency thereof, nor any of their employees, makes any warranty, express or implied, or assumes any legal liability or responsibility for the accuracy, completeness, or usefulness of any information, apparatus, product, or process disclosed, or represents that its use would not infringe privately owned rights. Reference herein to any specific commercial product, process, or service by trade name, trademark, manufacturer, or otherwise, does not necessarily constitute or imply its endorsement, recommendation, or favoring by the United States Government or any agency thereof. The views and opinions of authors expressed herein do not necessarily state or reflect those of the United States Government or any agency thereof. 
Isotope and Fuel Cycle Technology Division* Nuclear Nonproliferation Division ${ }^{\dagger}$

\title{
EFFICIENT ISOTOPE RECOVERY AND SEAMLESS RECYCLE OF TARGET MATERIAL IN A SALT MATRIX
}

\author{
David F. Williams ${ }^{\dagger}$ \\ Susan L. Hogle* \\ Guillermo D. DelCul ${ }^{*}$
}

September 2019

Prepared by

OAK RIDGE NATIONAL LABORATORY

Oak Ridge, TN 37831-6283

managed by

UT-BATTELLE, LLC

for the

US DEPARTMENT OF ENERGY

under contract DE-AC05-00OR22725 



\section{CONTENTS}

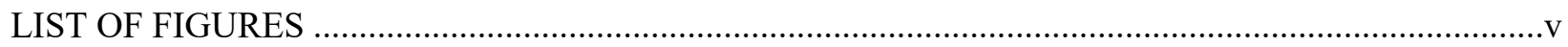

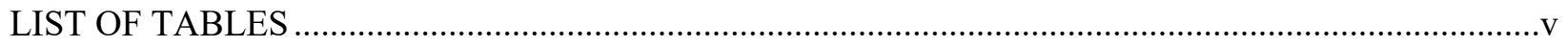

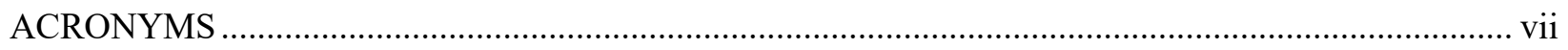

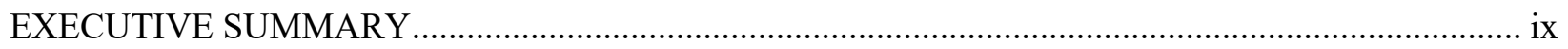

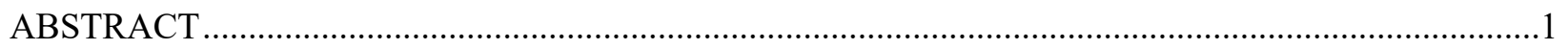

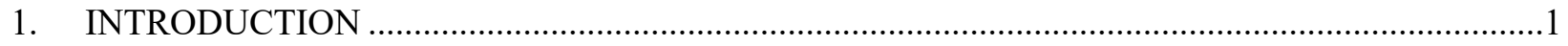

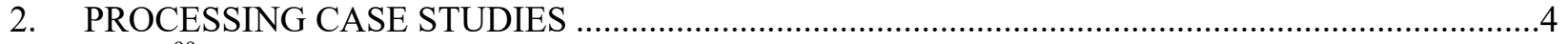

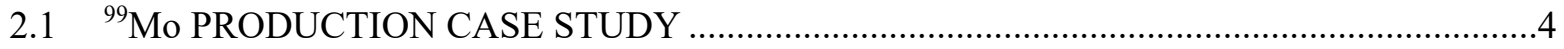

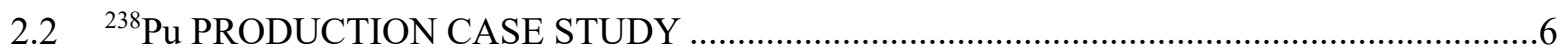

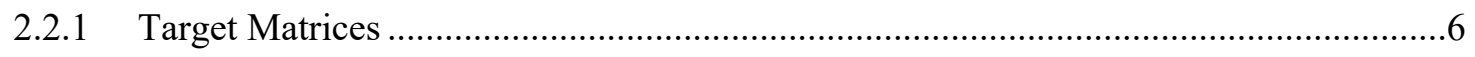

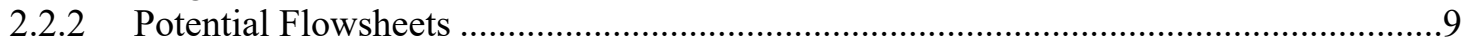

2.2.3 Screening Depletion Calculations .......................................................................... 10

3. REQUIREMENTS AND CONCEPTS FOR THERMAL CONTROL OF TARGETS ....................17

4. DEVELOPMENT PATHS FOR NEW TARGETS AND PROCESSES .........................................19

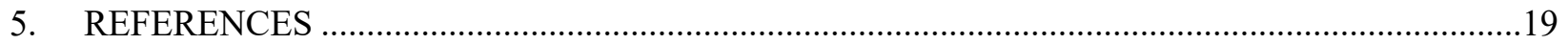

APPENDIX A. 2015 WHITEPAPER ON NON-AQUEOUS PROCESSING AND FISSION-

TARGET OPTIONS FOR ${ }^{99}$ MO PRODUCTION .................................................................. A-1 



\section{LIST OF FIGURES}

Figure 1. Noble-metal fission product isolation and purification for ${ }^{99}$ Mo production. ............................6

Figure 2. Halide and halide-salt target processing options for ${ }^{238} \mathrm{Pu}$ production. ...................................

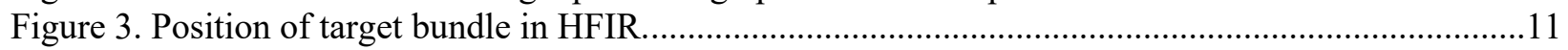

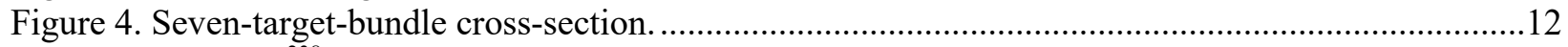

Figure 5. Trend of ${ }^{238} \mathrm{Pu}$ yield with neptunium density in target matrix...............................................15

Figure 6. Trend of neptunium utilization with neptunium density in target matrix.................................15

\section{LIST OF TABLES}

Table 1. Compositions, melting point, and densities of candidate salts for ${ }^{99}$ Mo production

Table 2. Compositions, melting points, and estimated densities (29) of select actinide-containing

salts 1
12
5

Table 3. Eutectic melting points for mixtures of trivalent and tetravalent actinides ... 8

Table 4. Alternative target materials considered for benchmarking Pu production calculations ................

Table 5. Pu yields for current and alternative target materials ....

Table 6. Pu vector by wt $\%$ for current and alternative target materials...

Table 7. Utilization and efficiency of utilization of $\mathrm{Np}$ for current and alternative target materials...........14

Table 8. Plutonium yield potential with cycling through active region of the reactor vessel.....................16 



\section{ACRONYMS}

HFIR High Flux Isotope Reactor

IRE Institute for Radioelements located in Fleurus, Belgium

MIT Massachusetts Institute of Technology

MSR Molten Salt Reactor

MSRE Molten Salt Reactor Experiment

ORNL Oak Ridge National Laboratory 



\section{EXECUTIVE SUMMARY}

Many isotope production technologies were developed decades ago and leveraged ongoing activities, infrastructure, and existing tools - they are not optimized to minimize life-cycle production costs using the tools available today. The use of halides as pure compounds or salt mixtures has the potential to significantly reduce overall cost by simplifying target production and post-irradiation processing, as well as minimizing the production of radioactive wastes.

This fiscal year 2019 Oak Ridge National Laboratory program development effort started with an assumption that attractive new capsule designs are one gating element to motivate the use of salt targets for isotope production. During this review, it became apparent that many salt choices are possible, and many potential design features could be used for isotope production. Consequently, the authors decided the limiting factor for motivating isotope production is likely not the absence of a suitable capsule design and that a broader analysis of the entire production cycle was needed. We conducted an overall systemslevel review of the various production pathways that highlighted which isotope applications would benefit most from a salt matrix target and in which parts of the process the benefit conferred.

The greatest overall benefit of a salt matrix target - as shown in Figure ES. 1 that outlines candidate processes - appears to be in applications such as ${ }^{99}$ Mo production by fission, where the product isotope might be extracted in a timely fashion, leaving the target isotope in the reactor for additional irradiation, boosting the target isotope inventory periodically by in-reactor additions to the capsule, and minimizing the demand for target fabrication, target transfer, and waste processing. A similar benefit can be realized for the production of ${ }^{232} \mathrm{U}$ by activation of ${ }^{230} \mathrm{Th} /{ }^{231} \mathrm{~Pa}$. However, in this case, the entire salt inventory would need to be removed from the reactor for processing by halide volatility, but the processed salt could be returned to the capsule for reirradiation after some straightforward treatments. This class of benefit for ${ }^{99} \mathrm{Mo}$ and ${ }^{232} \mathrm{U}$ production is referred to as "direct recycle of target isotope" in this report. For the special case of a $\mathrm{NpCl}_{\mathrm{x}}$ target for ${ }^{238} \mathrm{Pu}$ production, direct recycle of the target isotope may be possible using pyrochemical methods, but it is more likely an all-aqueous process would be adopted.

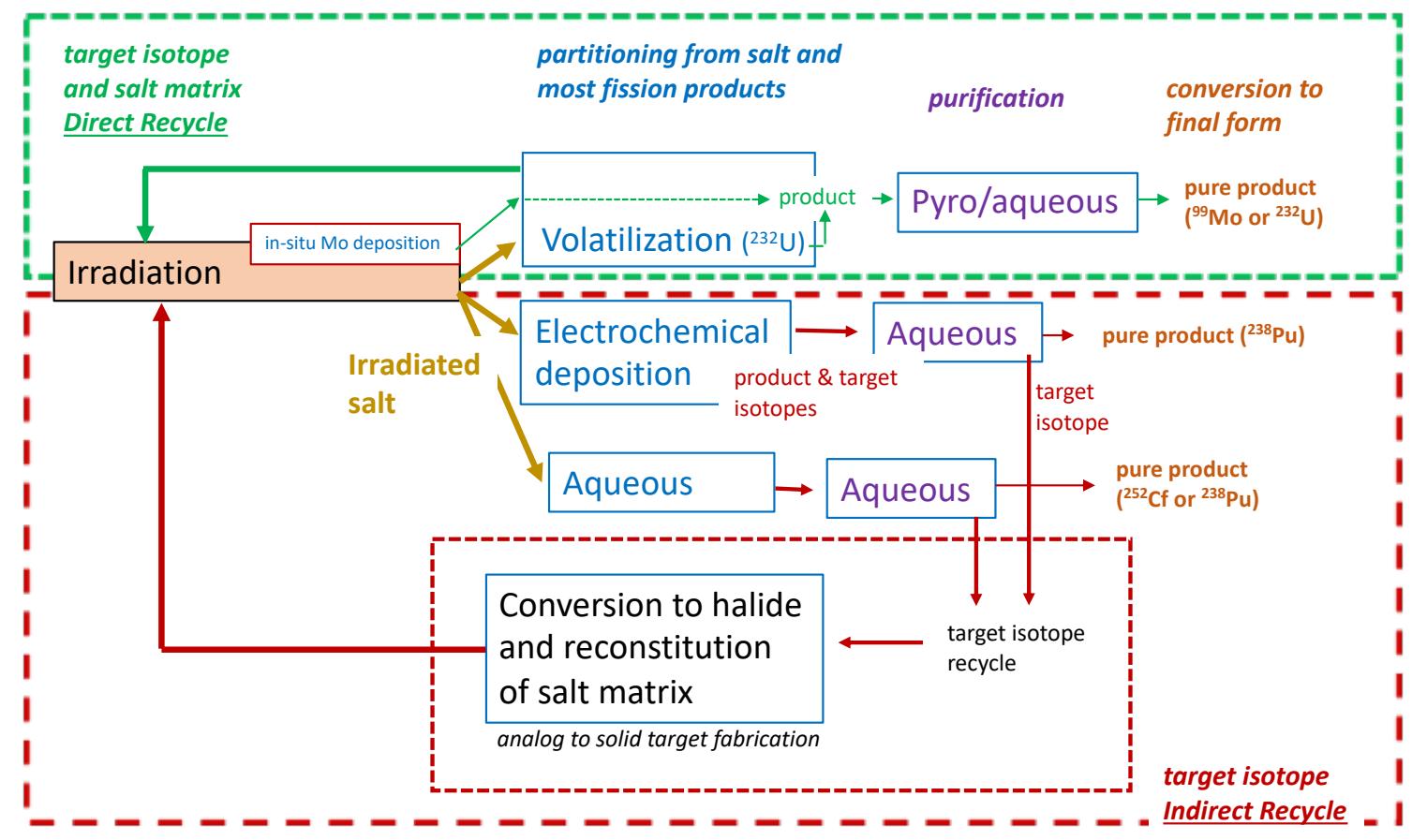

Figure ES-1. Comparison of processes for salt matrix isotope production case studies. 
For most of the ${ }^{238} \mathrm{Pu}$ production pathways and for heavy element production, the halide matrix is not retained throughout the recycle and must be reconstituted after processing. This reconstitution of the halide matrix and reintroduction in the capsule is an analog to solid-target fabrication. Even with this "indirect recycle" of target isotope, there are many potential advantages over currently used solid targets. For example, during salt matrix processing, there is no aluminum cladding to dissolve, and for chloride salts that readily dissolve in water, chloride solutions are often preferred for conducting several of the key separations. Reconstitution of the salt matrix in large batches for integration into the capsule may prove to be much more straightforward than fabrication of many small pellets into target rods. Both approaches require many operations and associated quality assurance steps to achieve specifications.

There may be benefits with the ability to cycle a mobile (e.g., molten salt) target matrix in and out of various irradiation zones to optimize isotope production. This capability exists for rabbit irradiations, but most solid-matrix production targets are typically in fixed locations. Our preliminary analysis of ${ }^{237} \mathrm{~Np}$ irradiation indicated that the primary benefit of cycling the bred ${ }^{238} \mathrm{~Np}$ out of the irradiation zone was to avoid parasitic fission that corresponded to a $7-17 \%$ reduction (depending on the shuttling schedule) in ${ }^{238} \mathrm{Pu}$ production in the comparable stationary target. The ${ }^{238} \mathrm{~Np}$ did not appear to shield the ${ }^{237} \mathrm{~Np}$ to any extent, and the self-shielding of ${ }^{237} \mathrm{~Np}$ appeared to be the dominant factor in limiting ${ }^{238} \mathrm{Pu}$ yields.

However, this target-shuttling action would significantly reduce fission product production and fission heat-load in the target. 


\begin{abstract}
A first step in developing molten salt nuclear reactors (MSRs) is a capability to irradiate capsules containing molten salts and a natural development path for this capability is through applications to produce radioisotopes using a molten salt matrix within existing water-cooled reactors. At present there is almost no capability to prepare, irradiate, and process salts for isotope production in the United States. This report documents an initial plan to create designs for capsules to produce various radioisotopes $\left({ }^{99} \mathrm{Mo},{ }^{238} \mathrm{Pu},{ }^{232} \mathrm{U}\right.$, and heavy elements) in a way that minimizes waste, simplifies (or in some cases eliminates the need for) recycle/refabrication operations by utilizing a salt matrix for irradiation and nonaqueous, aqueous, or hybrid processes for recovery of the isotopes from the salt matrix. The original fiscal year 2019 goals of this internal study were to
\end{abstract}

1. review past and current salt irradiation vehicle designs and evaluate modern materials, fabrication methods, and design methods to see how new vehicles could function for isotope production in the context of optimized nonaqueous or hybrid recovery methods and

2. engage potential end users with this approach, gather feedback, and provide recommendations for a phased implementation for different application/isotope domains.

While these remain worthly goals, it was recognized that a more strategic approach as outlined in the Executive Summary was needed before going into depth with regard to irradiation vehicle designs. This report fulfills the need for defining that more strategic approach.

Oak Ridge National Laboratory (ORNL) staff have developed a unique understanding of and capability for processing molten salts and related pyroprocessing methods. This capability can be sustained by passing it to a new generation and by tackling one of the challenging applications outlined in this report (or some other worthy isotope application) and putting the solution into practice. This study defines opportunities to start down that path.

\title{
1. INTRODUCTION
}

Halide salts readily host target isotopes, retain all necessary thermophysical and radiation stability properties to function in an irradiation target, and retain most fission products in the salt matrix for many irradiation cycles. Halide salts also offer the opportunity for selective removal of the product isotope and reirradiation of the matrix directly without the need for additional separation, conversion to a new matrix, and refabrication into a solid target.

To achieve seamless recovery of isotope product and direct recycle of the target matrix, new types of irradiation vehicles are needed. Previous efforts in irradiation testing of salts were either exploratory or tailored to address issues with the use of salt as a pumped fluid fuel in a molten salt reactor. The drivers and constraints for use of salts for isotope production are different and require new approaches to optimize the design of an isotope production system. Distinct requirements attend the production of particular isotopes and designs for halide salt targets will be different for different classes of production. Any salt-target design will need to control the temperature of the salt and surrounding materials within acceptable limits. Previous molten halide irradiations have been conducted both as static (non-flowing) capsules (1), (2), (3), (4), in pumped loops (5), and in natural convection loops. In one case, a Russian natural convection loop was used in conjunction with an internal heating element for startup (6), (7), and in another instance a natural convection loop was operated with external heaters at the Oak Ridge Research Reactor (8). 
For a few isotope production pathways, little heat is generated and a solid salt target might suffice as an irradiation matrix, but for many pathways intense heat is generated and a molten salt is needed as the target matrix. In the 1950s-1960s ORNL irradiated salts (typically in a beam hole external to the reactor core) in specialized rigs as static capsules of molten salt immersed in a $\mathrm{Na}$ or $\mathrm{NaK}$ bath to reject fission heat at temperatures significantly above the melting point of the salt $\left(\mathrm{T}>500^{\circ} \mathrm{C}\right)(1),(2)$. A few pumped flow loops were constructed at ORNL in the 1950 s with small tubing runs $(0.4$ in. outer diameter $\times$ 150 in. long), auxiliary heaters, and contained in a 5.5 in. pipe cooled by water on the outer surface and also cooled by an inert purge gas that swept through the experiment. These pumped flow loops were never intended for isotope production and do not provide much guidance on how to design/optimize a system for isotope production (5).

More recently irradiations have been conducted using static capsules. In 2014 an Massachusetts Institute of Technology (MIT) group began irradiation tests of an unfueled solid salt $\left({ }^{7} \mathrm{Li}_{2} \mathrm{BeF}_{4}\right)$ contained within a graphite crucible (9), (10). Starting in 2017 the High Flux Reactor-Petten SALIENT-1 capsule containing molten eutectic ${ }^{7} \mathrm{LiF}-\mathrm{ThF}_{4}$ salt in a graphite crucible was irradiated for $\sim 600$ days at $\sim 600^{\circ} \mathrm{C}$ and accumulated bred ${ }^{233} \mathrm{U}$ to achieve a specific target power of $\sim 35 \mathrm{~W} / \mathrm{g}$-salt (11). In 2018, ORNL and Ohio State University researchers conducted an initial low-fluence irradiation at the Ohio State Research Reactor of molten $\mathrm{KCl}-\mathrm{MgCl}_{2}$ salt to compare to existing corrosion studies on various materials (12).

To illustrate potential applications and development paths, four classes of isotope production that have distinct requirements and pose different types of design challenges are described below:

- activation matrix with minor fission levels (e.g., production of ${ }^{232} \mathrm{U}$ from ${ }^{230} \mathrm{Th}$ or ${ }^{231} \mathrm{~Pa}$ ),

- high-power fission matrix with short duration irradiations $\left({ }^{99} \mathrm{Mo}\right.$ and ${ }^{131} \mathrm{I}$ on a weekly basis),

- activation matrix with moderate fission levels for moderate duration irradiations $\left({ }^{238} \mathrm{Pu}\right.$ production),

- activation matrix with high fission levels for long duration irradiations (heavy element production, e.g., $\left.{ }^{252} \mathrm{Cf}\right)$.

For any of these applications a solid salt target is conceivable if the energy produced in the matrix is low enough and the matrix is conductive enough, but a rigorous understanding of when low-temperature radiolysis of the salt begins is needed (this radiolysis occurs below about $150^{\circ} \mathrm{C}$ for $2 \mathrm{LiF}-\mathrm{BeF}_{2}$ salts) and a means (heating, reductive capacity within the salt, or external halogen gas trapping) to prevent or mitigate radiolysis must be provided. Similar means to prevent or mitigate salt radiolysis will need to be provided for salts after irradiation, since the salt will continue to accumulate radiation exposure from fission and activation product decay.

Activation matrix with minor fission power levels: The production of ${ }^{232} \mathrm{U}$ from ${ }^{230} \mathrm{Th}\left(\right.$ or $\left.{ }^{231} \mathrm{~Pa}\right)$ is highlighted as an example of a largely non-fissioning ${ }^{*}$ salt matrix. ${ }^{232} \mathrm{U}$ had been considered as a candidate very-high-power radioisotope thermoelectric generator ${ }^{\dagger}$ many years ago (13). Salts such as the $\mathrm{NaF}-\mathrm{ThF}_{4}$ eutectic $\left(22 \mathrm{~mol}_{0} \mathrm{ThF}_{4}\right.$ or $51 \mathrm{wt} \% \mathrm{Th}$, salt density at $618^{\circ} \mathrm{C} \mathrm{mp} \sim 3.8 \mathrm{~g} / \mathrm{cc}$ ) provide a concentrated source of thorium in the form of a fluoride salt and permit a simple fluorination recovery of ${ }^{232} \mathrm{UF}_{6}$ from the irradiated salt in a single step. After a reducing treatment to remove any corrosion

\footnotetext{
${ }^{*}$ A minor amount of fission will occur due to fission of: ${ }^{232} \mathrm{U}$ and the small amount of ${ }^{233} \mathrm{U}$ produced by activation of ${ }^{232} \mathrm{U}$.

$\dagger$ The evaluation of ${ }^{232} \mathrm{U}$ in (13) was for a wide array of RTG applications — not soley a space travel application—and it was recognized that the intense gamma rays associated with ${ }^{208} \mathrm{Tl}$ would preclude its use in a number of applications due to the shielding requirements for the protection of electronic components and personnel.
} 
impurities introduced into the salt during fluorination, the salt can be returned to the irradiation capsule for reirradiation and additional production.

High-power fission matrix/short duration batch irradiations: A separate white paper included as Appendix A outlines the opportunity for salt matrix production and pyrorecovery of ${ }^{99} \mathrm{Mo}$. The key finding of the white paper is that reductive scavenging of insoluble fission products such as ${ }^{99} \mathrm{Mo}$ and its precursor ${ }^{99} \mathrm{Nb}$ might provide the most rapid and effective opportunity for harvesting this valuable fission product resource and providing an efficient means of recycling the target matrix for reirradiation. ${ }^{\ddagger}$ This concept of production would have as an option the removal of a surface (perhaps an electrode) from the capsule that contains ${ }^{99} \mathrm{Mo}$ (and ${ }^{99} \mathrm{Nb}$ and ${ }^{99} \mathrm{Zr}$ precursors) for further isolation and purification of the ${ }^{99} \mathrm{Mo}$ fraction by halide volatility in processing cell. The other recovery option evaluated included halide volatility processing of the entire salt. The halide volatility option has the disadvantage of producing a larger volume of radiovolatiles (including Te and I) that would not exist in the reductive isolation of ${ }^{99} \mathrm{Mo}$ as the Te and I (and other fission products) would remain in the salt under reducing conditions. Although the reductive processing option has more unknowns, it also has many more advantages and launches the research community into an exploration of fission product chemistry that is absolutely necessary for advances in molten salt technology (14).

Activation matrix with moderate fission levels for moderate duration irradiation: There exists a potential advantage for mobile fluid targets to optimize production of ${ }^{238} \mathrm{Pu}$ from irradiation of ${ }^{237} \mathrm{~Np}$. The control of the residence time of ${ }^{237} \mathrm{~Np}$ in the reactor flux on the scale of the ${ }^{238} \mathrm{~Np}$ decay (2.1 days) can provide a means to minimize the parasitic fission of ${ }^{238} \mathrm{~Np}$. The cyclic flow of a mobile salt target through the reactor on a short time scale (somewhat less than the 2.1 day half-life of ${ }^{238} \mathrm{~Np}$, perhaps just a day) combined with a holdup time of about 10 days (to allow the ${ }^{238} \mathrm{~Np}$ to decay to ${ }^{238} \mathrm{Pu}$ ) would minimize the parasitic fission of ${ }^{238} \mathrm{~Np}$ during neutron irradiation. This approach requires the holdup of more ${ }^{237} \mathrm{~Np}$ outside of the effective irradiation volume than that of a stationary solid target, but it would also involve far less loss to fission and far less production of fission product activity. A simple system could be devised to accomplish these types of back-and-forth flows, but maintenance of temperatures above the melting point of the salt would be essential for key parts of the apparatus. Another approach is a solid target to mechanically shuttle materials in and out of the irradiation zone.

${ }^{238} \mathrm{Pu}$ recovery could proceed along the traditional aqueous line with the salt anion (likely chloride) replacing nitrate anion in the first steps, but more appealing would be a partitioning of $\mathrm{Pu}$ from $\mathrm{Np}$ in the salt (perhaps by electroreduction or electrodeposition), thus permitting the stripped molten salt to be boosted with some additional ${ }^{237} \mathrm{~Np}$ feed and returned to the reactor for additional production. Should selective removal of $\mathrm{Pu}$ from the salt prove practical - cyclic harvest of ${ }^{238} \mathrm{Pu}$ from the batches described in the previous paragraph could further minimize production of ${ }^{239} \mathrm{Pu}$ and related parasitic fission. The options for selecting the target matrix and conducting the separations needed for ${ }^{238} \mathrm{Pu}$ production are discussed and analyzed in more detail in the next section. A first order analysis of the activation and depletion effects of changing the target matrix from the current cermet and $\mathrm{NpO}_{2}$ designs to various salt matrix options are also considered in Section 2.2.3.

Activation matrix with high fission levels for long duration irradiations (heavy element production, e.g., ${ }^{252} \mathrm{Cf}$ ): Halide salts possess the fundamental properties needed to endure the extreme conditions of flux and burnup required for heavy element production. The container materials for the salt are likely more limiting than the salt itself for irradiation durability. Because of the extremely difficult and highresolution separations required to fractionate heavy elements, it is expected that the final steps to fractionate heavy elements will be aqueous separations, but if an initial pyroprocessing step can harvest

\footnotetext{
$\$$ Only about $3 \%$ of the ${ }^{235} \mathrm{U}$ in current solid targets is fissioned to produced ${ }^{99} \mathrm{Mo}$ - the remainder is discarded as waste (14).
} 
heavy element products from the target elements and allow recycle of the salt target - it would be of great benefit.

It is not readily apparent if a benefit can be achieved by allowing intermediate isotopes to decay (i.e., a cooling period delay) in the activation chain to produce ${ }^{252} \mathrm{Cf}$, as there is in the production of ${ }^{238} \mathrm{Pu}$. However, the capability to move the fluid target material to different irradiation zones (with the potential for fluxes and neutron energies tailored by the target design or auxiliary systems) during these long irradiation periods might prove beneficial and is worth investigation. Currently there is no flexibility to change the irradiation location of full-length isotope targets in the central target bundle at the ORNL High Flux Isotope Reactor (HFIR) during a single irradiation cycle.

\section{PROCESSING CASE STUDIES}

We adopted a screening approach that first looked for attractive processing options for target matrices that might be suitable for irradiation - perhaps requiring advanced designs for the irradiation target system. If an attractive processing option could not be identified, target designs for a particular irradiation matrix should not be considered. It was apparent from our initial survey that attractive processing options could be identified for ${ }^{232} \mathrm{U}$ production and might be present for ${ }^{99}$ Mo production. For the case of ${ }^{232} \mathrm{U}$ production, halide volatility is the most attractive flowsheet and there is little need to elaborate further because it parallels (but can be simpler than) the recovery of ${ }^{235} \mathrm{U}$ from the Molten Salt Reactor Experiment (MSRE) (15), (16). For the case of ${ }^{99}$ Mo recovery, the chemistry of near-noble and noble fission products, as well as their precursors in molten halides, is not well understood, but what is known (17), (18), (19), (20), (21), (22) provides some hope for pursuing online isolation of the noble metals (including Mo). Our case study of this high-priority isotope is described in the next section, supporting materials are provided in Appendix A, and development paths are outlined later in the report.

Because ${ }^{238} \mathrm{Pu}$ production is a pressing issue and will continue to be of interest for many years, we devoted most of our effort to this case study. We approached the option of ${ }^{238} \mathrm{Pu}$ production in halide matrices as an open question because no obvious barrier or solution was apparent at first.

The production of heavy elements is such a challenging application and high-resolution pyroseparation of very similar transplutonium elements seemed so difficult that we decided not to take on heavy element production as a case study. The application of a chloride salt target for irradiation of a transplutonium target in conjunction with proven aqueous separations is possible and might not need any new processing steps - the processing would be nearly identical (or a little simpler) than the existing transplutonium element flowsheets (23). ${ }^{\S}$

\subsection{MOLYBDNEUM-99 PRODUCTION CASE STUDY}

Uranium-containing halide salt for ${ }^{99}$ Mo production: Because of the very high fission-heat produced in this target, only molten halides (rather than solid salts) are suitable for shuttling the large heat flux to the capsule boundary in a controlled and safe manner - the thermal conductivity of solid halides is too low to maintain the salt below the melting point for such large heat fluxes. To minimize the target matrix volume, we favor salts with the highest U-density. From the standpoint of heat transfer efficiency, we favor salts with the solvent (i.e., non-uranium) constituents that have the lowest atomic number. Lower melting point salts are also favored for the ease of matrix preparation and target design/flexibility. Given these priorities, it would appear that a fluoride salt such as ${ }^{7} \mathrm{LiF}-\mathrm{UF}_{4}$ or ${ }^{7} \mathrm{LiF}-\mathrm{NaF}-\mathrm{UF}_{4}$ or ${ }^{7} \mathrm{LiF}-\mathrm{RbF}-\mathrm{UF} 4$ would be favored. If a salt without enriched light elements is required, the $\mathrm{NaF}-\mathrm{RbF}-\mathrm{UF}_{4}$ salt would be

\footnotetext{
$\S$ However, developments that led to the use of an initial stage of nitric acid-based processes identified in (23) must be revisited and options evaluated given the changes in feedstock and other separations possibilities.
} 
favored. Fluoride salts with lower melting points $\left(<430^{\circ} \mathrm{C}\right)$, such as $\mathrm{NaF}-\mathrm{BeF}_{2}-\mathrm{UF}_{4}$ and ${ }^{7} \mathrm{Li}-\mathrm{BeF}_{2}-\mathrm{UF}_{4}$, are also candidates if Be-containing systems can be considered. These options are summarized below along with a few chloride salt analogs.

Chloride salts can contain enough uranium to be considered but exhibit poorer heat transfer performance than fluorides and might require chlorine enrichment to remove the ${ }^{35} \mathrm{Cl}$ that is responsible for considerable parasitic absorption (and sulfur production). These neutronic penalties also apply to the use of chlorine for ${ }^{238} \mathrm{Pu}$ production and are evaluated in Section 2.2.3 of this report.

Chlorides have the benefit of easily dissolving in water and placing fewer new demands on ORNL (and perhaps other) tank infrastructure and waste treatment systems than fluorides. In fact, if fluorides were used, nonaqueous processes would likely be the mainstay of salt processing, ${ }^{* *}$ whereas for chlorides aqueous or nonaqueous processing could be used (24), (25), (26).

Table 1. Compositions, melting point, and densities of candidate salts for ${ }^{99}$ Mo production

\begin{tabular}{|c|c|c|c|c|}
\hline Eutectic salt mixture & $\underset{\mathrm{UCl}_{3}}{\operatorname{Mole} \% \mathrm{UF}_{4} \text { or }}$ & $\begin{array}{c}\text { Melting } \\
\text { point }\left({ }^{\circ} \mathbf{C}\right)\end{array}$ & $\begin{array}{c}\text { Density (gm- } \\
\mathrm{U} / \mathrm{cc} \text { at } \\
\left.600^{\circ} \mathrm{C}\right)^{a}\end{array}$ & $\begin{array}{c}\text { gm-U in 61- } \\
\text { cc }^{b}\end{array}$ \\
\hline${ }^{7} \mathrm{LiF}-\mathrm{UF}_{4}$ & 27 & 490 & 2.91 & 178 \\
\hline $\mathrm{NaF}-\mathrm{UF}_{4}$ & 28 & 623 & 2.52 & 154 \\
\hline${ }^{7} \mathrm{LiF}-\mathrm{NaF}-\mathrm{UF}_{4}$ & 32 & 445 & 2.91 & 178 \\
\hline $\mathrm{NaF}-\mathrm{RbF}-\mathrm{UF}_{4}$ & 21 & 470 & 1.69 & 103 \\
\hline $\mathrm{NaF}-\mathrm{BeF}_{2}-\mathrm{UF}_{4}$ & 10 & 486 & 1.10 & 67 \\
\hline $\mathrm{NaF}-\mathrm{BeF}_{2}-\mathrm{UF}_{4}$ & 1 & 378 & 0.11 & 7 \\
\hline${ }^{7} \mathrm{LiF}_{-} \mathrm{BeF}_{2}-\mathrm{UF}_{4}$ & 8 & 426 & 1.04 & 63 \\
\hline $\mathrm{NaCl}-\mathrm{UCl}_{3}$ & 33 & 520 & & \\
\hline${ }^{7} \mathrm{LiCl}-\mathrm{KCl}-\mathrm{UCl}_{3}$ & 33 & 408 & & \\
\hline${ }^{7} \mathrm{LiCl}-\mathrm{KCl}-\mathrm{UCl}_{3}$ & 8 & 346 & & \\
\hline $\mathrm{NaCl}-\mathrm{MgCl}_{2}-\mathrm{UCl}_{3}$ & 11 & 446 & & \\
\hline
\end{tabular}

${ }^{a}$ Densities based on additive molar volumes if the molar volumes were found in the literature.

${ }^{b}$ A 61-cc volume is the volume of a single ${ }^{99}$ Mo target used by the IRE and contains $4 \mathrm{~g}$ of uranium.

The primary driver for considering salts for ${ }^{99}$ Mo production is the potential to reuse the salt matrix and the opportunity to efficiently and rapidly extract the ${ }^{99} \mathrm{Mo}$ and sequester and accumulate the fission products in the salt in such a way that it imposes far fewer demands on the radioactive waste and effluent control systems. As ${ }^{99}$ Mo itself does not dissolve in molten salts, but rather plates out on surfaces immersed in or adjacent to the salt, we envision a system that leaves the salt in the irradiation capsule for many cycles but processes some internal surface in the capsule to recover the ${ }^{99}$ Mo for each weekly production cycle. Furthermore, it is not necessary to transition to aqueous chemistry immediately because halide volatility processing will rapidly and effectively mobilize and isolate ${ }^{99} \mathrm{Mo}$ from other noble metal fission products and any tramp uranium that is carried over. The isolated $\mathrm{MoF}_{6}\left(\right.$ or $\left.\mathrm{MoCl}_{6}\right)$ can then be introduced into an aqueous solution for conventional aqueous purification. This approach is outlined below in Figure 1.

\footnotetext{
** Although fluorides do not readily dissolve in water, with the application of a number of digestion agents they can be fused and solubilized (24), (25), (26). If an all-aqueous flowsheet is desired, these methods should be evaluated.
} 


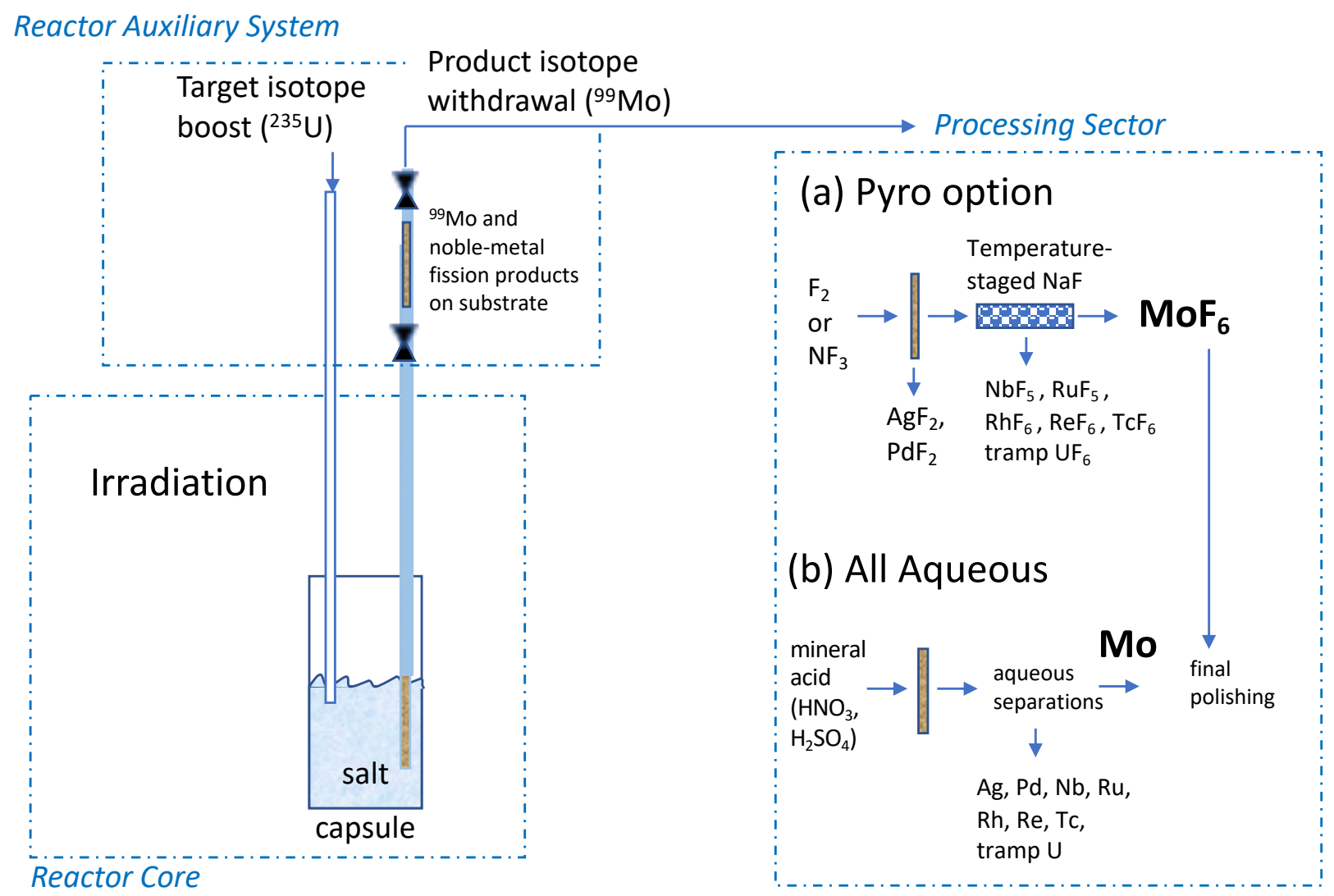

Figure 1. Noble metal fission product isolation and purification for ${ }^{99} \mathrm{Mo}$ production.

There will be a limit to the number of cycles the salt can be reused in a capsule due to buildup of fission products - once this limit is reached the salt will need to be processed or discarded. However it is likely that quite a large number of salt reuse cycles can be supported because only about $3 \%$ of the uranium is typically fissioned in the 1 week ${ }^{99}$ Mo irradiation cycle (14). As in past assessments (27), the solubility of trivalent rare earths and their influence on increasing the salt melting point is most likely the limiting fission product buildup factor. Boosting the uranium content of the salt to counterbalance its loss due to fission is straightforward, but this mechanism must be provided for in the system design. The purification operations that work in concert with this proposed reuse of the salt must also demonstrate that the ${ }^{99} \mathrm{Mo}$ product meets all Food and Drug Adminstration specifications for all cycles of irradiation.

\subsection{PLUTONIUM-238 PRODUCTION CASE STUDY}

\subsubsection{Target Matrices}

Neptunium-containing halide for ${ }^{238} \mathrm{Pu}$ production: The documentation of halide salt compounds and salt compositions containing uranium and plutonium is extensive, but the literature for neptunium salts is far more limited. In fact, very few ${ }^{\dagger \dagger}$ salt phase diagrams exist for mixtures of a neptunium halide and another salt constituent. When uranium and plutonium halide compounds exist in the same oxidation state

\footnotetext{
$\dagger$ We found none.
} 
(as is the case for chloride salt mixtures in which both elements tend to exist in the +3 oxidation state) their phase diagrams show a marked similarity, with eutectic temperatures and compositions falling close to one another as shown in Table 1 . As neptunium also exists in a +3 oxidation state in chloride salt mixtures that are usefully noncorrosive, it is very likely the neptunium chloride salt mixtures have eutectic temperatures and compositions close to those of $\mathrm{UCl}_{3}$ and $\mathrm{PuCl}_{3}$ mixtures.

For fluoride salts, the predominant oxidation state for $\mathrm{U}$ is +4 and that for $\mathrm{Pu}$ is +3 , and a previous study indicates $\mathrm{Np}$ exists primarily as $\mathrm{Np}(\mathrm{IV})$; consequently, $\mathrm{Np}$ salts likely exhibit eutectic temperatures and compositions similar to those listed for U(IV) fluoride salt mixtures listed in Table 2.

There is another approach to considering the target matrix that does not require a molten salt mixture. In this alternate approach, we consider using the Np halide directly as a solid that is undiluted by any other salt component. Although there is no reported melting point for either $\mathrm{NpF}_{3}$ or $\mathrm{NpF}_{4}$ - these compounds are certainly refractory, and their melting points are likely intermediate between the $\mathrm{U}$ and $\mathrm{Pu}$ trifluoride $\left(1396-1497^{\circ} \mathrm{C}\right)$ and tetrafluoride $\left(1027-1036^{\circ} \mathrm{C}\right)$ analogs. Although dense and high melting - attractive features for a target material - these compounds would require intense fluorine chemistry for both preparation (akin to that needed to prepare $\mathrm{UF}_{4}$ from $\mathrm{UO}_{2}$ or $\mathrm{UF}_{6}$ ) and recycling into the next target.

The use of a molten fluoride salt mixture would likely require fluoride volatility recovery of $\mathrm{NpF}_{6}$ and reconstitution of $\mathrm{NpF}_{4}$ from $\mathrm{NpF}_{6}$, and a complex pyrochemical or mix of pyrochemical and aqueous steps for $\mathrm{Pu}$ recovery and purification. The transition to aqueous processing chemistry does not appear attractive as fluorides salts dissolve slowly in water and have low relatively low solubilities; furthermore, for an aqueous route a significant amount of fluoride would be discarded and then demanded anew for reconstitution of the target. The imposition of the additional alpha-n source term when fluorine is comingled with high-alpha materials is another potential drawback.

The chlorides of neptunium provide some different - and potentially attractive - production possibilities. Among the most important features of the neptunium chlorides is the potential to recover the target matrix directly by distillation of $\mathrm{NpCl}_{4}$, leaving $\mathrm{PuCl}_{3}$ in the nonvolatile heel for recovery and purification by aqueous or nonaqueous means (28). $\mathrm{NpCl}_{3}$ or $\mathrm{NpCl}_{4}$ could be used as the target matrix, but because liquid $\mathrm{NpCl}_{4}$ is potentially corrosive, its irradiation stability is not known, and it might need to be contained in graphite rather than metal $-\mathrm{NpCl}_{3}$ is a likely a more stable irradiation matrix. After irradiation, a $\mathrm{NpCl}_{3}$ matrix would be melted and converted to $\mathrm{NpCl}_{4}$ by a chlorinating agent, and the $\mathrm{NpCl}_{4}$ would be distilled (perhaps in two stages), leaving nonvolatile fission products and $\mathrm{PuCl}_{3}$ in the heel. $\mathrm{NpCl}_{4}$ is readily converted back to $\mathrm{NpCl}_{3}$ with $\mathrm{H}_{2}$ or zinc metal if $\mathrm{NpCl}_{3}$ is the desired irradiation matrix. Either $\mathrm{NpCl}_{4}$ or $\mathrm{NpCl}_{3}$ can be melted and cast into the target chamber, which should remove a considerable amount painstaking fabrication needed for mating the target matrix with cladding. An important drawback for the use of chloride salts is the relatively high absorption cross section of ${ }^{35} \mathrm{Cl}$, and both natural chlorine and enriched ${ }^{37} \mathrm{Cl}$ are evaluated for this application in Section 2.2.3.

A $\mathrm{NpCl}_{4}-\mathrm{NpCl}_{3}$ mixture will likely exhibit a eutectic similar to that exhibited by other actinide mixtures of trivalent and tetravalent halides. Table 3 indicates such a eutectic mixture for $\mathrm{NpCl}_{4}-\mathrm{NpCl}_{3}$ might show a melting point depression of nearly $100^{\circ} \mathrm{C}$ (lowering the melting point to about $438^{\circ} \mathrm{C}$ ). 
Table 2. Compositions, melting points, and estimated densities (29) of select actinide-containing salts

\begin{tabular}{|c|c|c|c|}
\hline \multicolumn{4}{|c|}{ Fluoride Mixtures } \\
\hline & $\begin{array}{l}\text { Mole \% } \\
\text { actinide } \\
\text { halide }\end{array}$ & $\begin{array}{c}\text { Melting } \\
\text { point }\left({ }^{\circ} \mathbf{C}\right)\end{array}$ & $\begin{array}{l}\text { Actinide density } \\
\text { at } 600^{\circ} \mathrm{C}(\mathrm{gm}- \\
\text { actinide/cc) }\end{array}$ \\
\hline${ }^{7} \mathrm{LiF}-\mathrm{UF}_{4}$ & 27 & $490^{\circ} \mathrm{C}$ & 2.91 \\
\hline $\mathrm{NaF}-\mathrm{UF}_{4}$ & 28 & $623^{\circ} \mathrm{C}$ & 2.52 \\
\hline $\mathrm{RbF}-\mathrm{UF}_{4}$ & 43.5 & $675^{\circ} \mathrm{C}$ & 2.66 \\
\hline${ }^{7} \mathrm{LiF}-\mathrm{NaF}-\mathrm{UF}_{4}(24-44-32$ mole\% $\%)$ & 32.2 & $445^{\circ} \mathrm{C}$ & 2.91 \\
\hline${ }^{7} \mathrm{LiF}-\mathrm{RbF}-\mathrm{UF}_{4}(40-20-40$ mole$\%)$ & 40 & $<500^{\circ} \mathrm{C}$ & 3.14 \\
\hline $\mathrm{NaF}-\mathrm{RbF}-\mathrm{UF}_{4}(44-33-21$ mole$\%)$ & 21 & $470^{\circ} \mathrm{C}$ & 1.69 \\
\hline${ }^{7} \mathrm{LiF}-\mathrm{PuF} 3$ & 19.5 & $743^{\circ} \mathrm{C}$ & \\
\hline $\mathrm{NaF}-\mathrm{PuF}{ }_{3}$ & 24 & $727^{\circ} \mathrm{C}$ & \\
\hline \multicolumn{4}{|c|}{ Chloride Mixtures } \\
\hline${ }^{7} \mathrm{LiCl}-\mathrm{PuCl}_{3}$ & 28 & $461^{\circ} \mathrm{C}$ & 1.71 \\
\hline${ }^{7} \mathrm{LiCl}-\mathrm{UCl}_{3}$ & 25 & $490^{\circ} \mathrm{C}$ & \\
\hline $\mathrm{NaCl}-\mathrm{PuCl}_{3}$ & 36 & $453^{\circ} \mathrm{C}$ & - \\
\hline $\mathrm{NaCl}-\mathrm{UCl}_{3}$ & 33 & $520^{\circ} \mathrm{C}$ & \\
\hline $\mathrm{NaCl}-\mathrm{UCl}_{4}$ & 47 & $370^{\circ} \mathrm{C}$ & \\
\hline $\mathrm{KCl}-\mathrm{PuCl}_{3}$ & 57 & $486^{\circ} \mathrm{C}$ & - \\
\hline $\mathrm{KCl}-\mathrm{UCl}_{3}$ & 57 & $532^{\circ} \mathrm{C}$ & \\
\hline $\mathrm{RbCl}-\mathrm{UCl}_{3}$ & 45.5 & $513^{\circ} \mathrm{C}$ & \\
\hline $\mathrm{RbCl}-\mathrm{PuCl}_{3}$ & 50 & $504^{\circ} \mathrm{C}$ & 2.01 \\
\hline${ }^{7} \mathrm{LiCl}-\mathrm{KCl}-\mathrm{UCl}_{3}(42-25-33$ mole $\%)$ & 33 & $408^{\circ} \mathrm{C}$ & \\
\hline${ }^{7} \mathrm{LiCl}-\mathrm{KCl}-\mathrm{UCl}_{3}(50-42-8$ mole$\%)$ & 8 & $346^{\circ} \mathrm{C}$ & \\
\hline $\mathrm{NaCl}-\mathrm{MgCl}_{2}-\mathrm{UCl}_{3}(64-25-11 \mathrm{~mole} \%)$ & 11 & $446^{\circ} \mathrm{C}$ & \\
\hline $\mathrm{NaCl}-\mathrm{MgCl}_{2}-\mathrm{PuCl}_{3}(63-17-20$ mole $\%)$ & 20 & $424^{\circ} \mathrm{C}$ & \\
\hline
\end{tabular}

\begin{tabular}{|l|c|c|c|}
\hline \multicolumn{4}{|c|}{ Single Compound Halides and Oxides } \\
\hline & $\begin{array}{c}\text { Formula } \\
\text { weight }\end{array}$ & $\begin{array}{c}\text { Melting point } \\
\left({ }^{\circ} \mathbf{C}\right)\end{array}$ & $\begin{array}{c}\text { Actinide density at } \\
\mathbf{2 5}^{\circ} \mathbf{C} \text { (gm- } \\
\text { actinide/cc) }\end{array}$ \\
\hline $\mathrm{UF}_{4}$ & 314 & $1036^{\circ} \mathrm{C}$ & 5.1 \\
\hline $\mathrm{UF}_{3}$ & 295 & $1495^{\circ} \mathrm{C}$ & 7.2 \\
\hline $\mathrm{UCl}_{3}$ & 344 & $837^{\circ} \mathrm{C}$ & 3.8 \\
\hline $\mathrm{UCl}_{4}$ & 380 & $590^{\circ} \mathrm{C}$ & 3.1 \\
\hline $\mathrm{PuF}_{4}$ & 320 & $1027^{\circ} \mathrm{C}$ & 5.3 \\
\hline $\mathrm{PuF}_{3}$ & 301 & $1396^{\circ} \mathrm{C}$ & 7.4 \\
\hline $\mathrm{PuCl}_{3}$ & 345 & $767^{\circ} \mathrm{C}$ & 3.9 \\
\hline $\mathrm{PuCl}_{4}$ & 386 & $6 a 5 e 0 u s$ & 3.7 \\
\hline $\mathrm{NpCl}_{3}$ & 343 & $800^{\circ} \mathrm{C}$ & 3.1 \\
\hline $\mathrm{NpCl}_{4}$ & 379 & $538^{\circ} \mathrm{C}$ & 9.8 \\
\hline $\mathrm{NpO}_{2}$ & & & \\
\hline
\end{tabular}

${ }^{a}$ densities for pure compounds were used to estimate mixture density using additive molar volumes when individual

compound molar volume was available in the literature (29). 
Table 3. Eutectic melting points for mixtures of trivalent and tetravalent actinides

\begin{tabular}{|c|c|c|c|c|c|c|c|}
\hline $\begin{array}{l}\text { Trivalent } \\
\text { compound }\end{array}$ & $\begin{array}{l}\text { Tetravalent } \\
\text { compound }\end{array}$ & $\begin{array}{c}\stackrel{\mathrm{A}}{\text { trivalent }} \\
\text { melting } \\
\text { point }\left({ }^{\circ} \mathbf{C}\right)\end{array}$ & $\begin{array}{c}\text { B tetravalent } \\
\text { melting } \\
\text { point }\left({ }^{\circ} \mathbf{C}\right)\end{array}$ & $\begin{array}{c}\stackrel{\mathrm{C}}{\text { Eutectic }} \\
\text { temperature } \\
\left({ }^{\circ} \mathrm{C}\right)\end{array}$ & $\begin{array}{c}\Delta=\mathbf{B}-\mathbf{C} \\
\left({ }^{\circ} \mathbf{C}\right)\end{array}$ & $\underline{\Delta /(B+273)}$ & $\begin{array}{c}\text { mole fraction } \\
\text { of tetravalent } \\
\text { component in } \\
\text { eutectic }\end{array}$ \\
\hline $\mathrm{UF}_{3}$ & $\mathrm{UF}_{4}$ & 1495 & 1036 & 865 & 171 & 0.13 & 0.68 \\
\hline $\mathrm{UCl}_{3}$ & $\mathrm{UCl}_{4}$ & 837 & 590 & - & - & - & - \\
\hline $\mathrm{PuCl}_{3}$ & $\mathrm{ThCl}_{4}$ & 770 & 762 & 620 & 142 & 0.14 & 0.67 \\
\hline $\mathrm{CeF}_{3}$ & $\mathrm{ThF}_{4}$ & 1460 & 1110 & 950 & 160 & 0.12 & 0.75 \\
\hline $\mathrm{NpCl}_{3}$ & $\mathrm{NpCl}_{4}$ & 800 & 538 & $433^{a}$ & $105^{a}$ & $0.13^{a}$ & - \\
\hline
\end{tabular}

${ }^{a}$ Estimate based on $\mathrm{U}, \mathrm{Pu}$, and $\mathrm{Ce}$ trend.

\subsubsection{Potential Flowsheets}

Prior work with $\mathrm{Np}$ and other actinides supports preliminary screening of aqueous, volatility, and electrochemical flowsheets for isolation and purification ${ }^{238} \mathrm{Pu}$ and recycle of ${ }^{237} \mathrm{~Np}$. The basic features of these different classes of separations are shown in Figure 2.

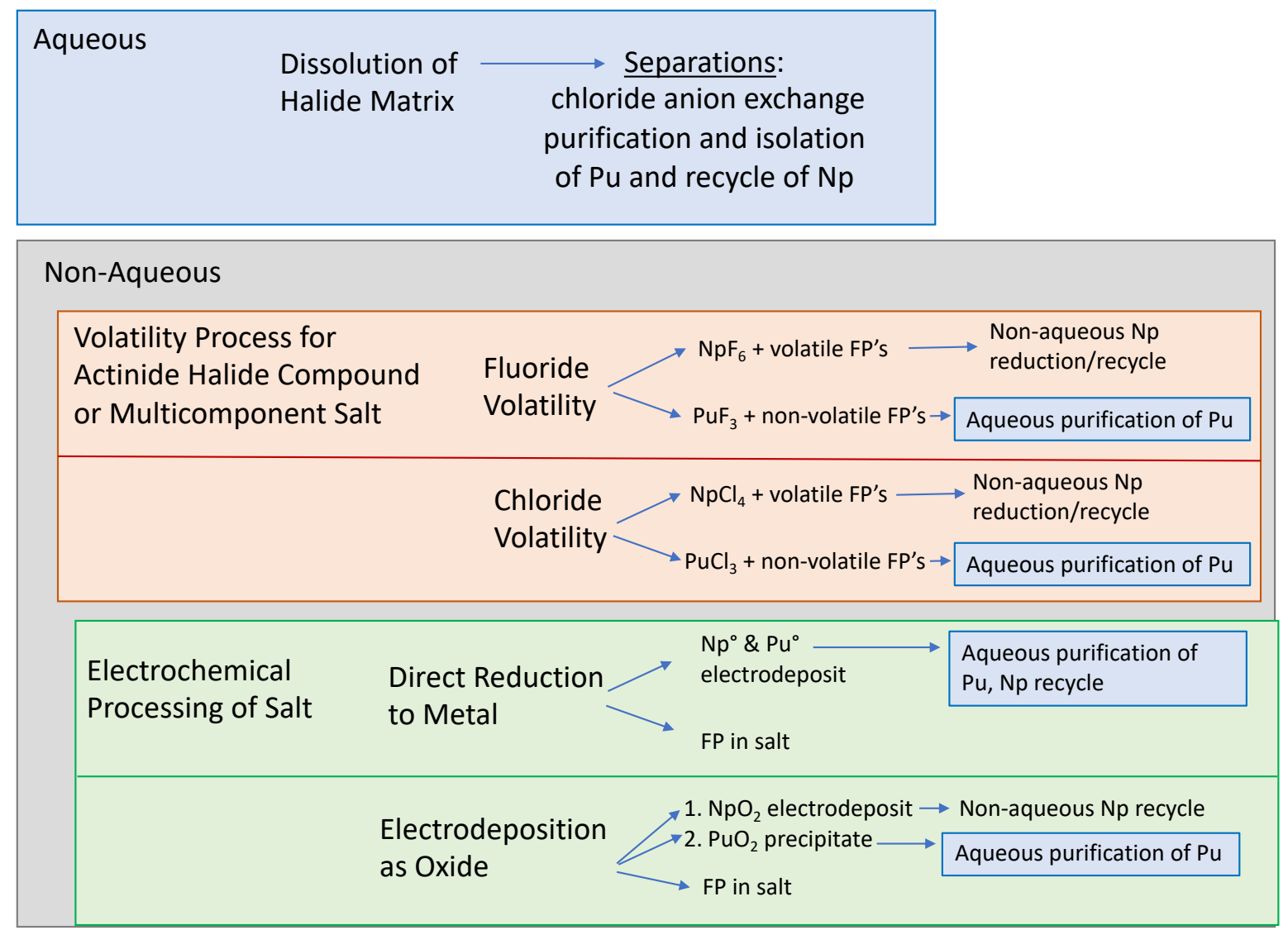

Figure 2. Halide and halide-salt target processing options for ${ }^{238} \mathrm{Pu}$ production.

An all-aqueous process entails dissolution of the salt (likely a chloride) in dilute acid followed by highresolution anion exchange separations. South Korean researchers and others have demonstrated 
fractionation of $\mathrm{Np}$ and $\mathrm{Pu}$ on anion resin in aqueous chloride solutions (30), (31), (32), (33) which could be simpler than the current caustic dejacketing followed by a nitric acid dissolution and a combination of solvent extraction and ion exchange. The $\mathrm{Np}$ recovered as an aqueous solution would need to be reconstituted as anhydrous $\mathrm{NpCl}_{3}$ or $\mathrm{NpCl}_{4}$ for use in a subsequent irradiation cycle.

As shown in Figure 2 volatility processes can isolate and purify $\mathrm{Np}$ as volatile halide, but the Pu product will require aqueous purification to meet the purity and morphology specifications for radioisotope thermoelectric generators. Although the isolated volatile $\mathrm{Np}$ halide could be readily reduced and directly reincorporated into the target, the salt matrix (if a pure $\mathrm{Np}$ halide is not used) would need to be reconstituted from scratch. In this case, it is not clear that a volatility flowsheet that includes a multistage combination of both pyro and aqueous operations is more advantageous than an all-aqueous process.

Studies indicate (34) that during direct electroreduction to metal of $\mathrm{Np}$ and $\mathrm{Pu}$ from halide salts, separating these two elements is difficult. Russian studies (35) showed that oxide-driven separation of actinides from molten halides could be achieved: first $\mathrm{NpO}_{2}$ is electrodeposited, and then the remaining $\mathrm{Pu}$ can be precipitated as an oxide that settles to the bottom of the container. Again, the $\mathrm{Pu}$ that is partitioned will still need to be purified by high-resolution aqueous separations to meet radioisotope thermoelectric generator specifications.

We looked for - but did not find - a separations scheme that selectively removes Pu from the salt and leaves the $\mathrm{Np}$ in the salt so it can be directly recycled in the next irradiation. A 1972 review of Np separations technology (36) also did not identify any pyroseparations for selectively removing Pu from $\mathrm{Np}$ and leaving the $\mathrm{Np}$ in the salt matrix. If we had found such an attractive separation, it would function in the direct recycle mode described in this report for ${ }^{99} \mathrm{Mo}$ and ${ }^{232} \mathrm{U}$ production.

In summary, we identified the following flowsheets:

- An all-aqueous processing flowsheet may provide a simpler process than is currently used for Pu purification and $\mathrm{Np}$ isolation, purification, and recycle; however, it does not support direct recycle of the salt matrix.

- Volatility flowsheets can selectively isolate and recycle $\mathrm{Np}$ but do not support direct recycle of the salt matrix (if a multicomponent salt is used rather than a pure $\mathrm{Np}$-halide) and would require aqueous purification of the Pu stream.

- Electrochemical flowsheets can isolate $\mathrm{Pu}$ and $\mathrm{Np}$ from the salt matrix and most fission products, but aqueous purification of the $\mathrm{Pu}$ stream will be required. In most instances, the salt matrix could be reused.

\subsubsection{Screening Depletion Calculations}

Irradiation simulations were completed using a combination of the Monte Carlo n-Particle transport code (MCNP) and the depletion module ORIGEN-S from the SCALE code system. Simulations assumed that the same physical geometry would be used for each ${ }^{238} \mathrm{Pu}$ production target, so that an effective comparison of the impacts of the material could be assessed. The geometry used is that of a seven-target bundle placed into position 3 of the inner small vertical experimental facility (VXF-3) of HFIR. This is the same geometry that is presently used for production of ${ }^{238} \mathrm{Pu}$ from cermet oxide targets. Irradiation was simulated for two 25 day cycles of irradiation with an 18 day period of decay between each cycle, which is typical of HFIR operations. A simulation of the cermet oxide targets was validated by comparison with analysis by Chandler (37), and the calculated yields were within 5\% of those obtained 
by Chandler. The design of the target bundle is shown in Figures 3 and 4, and the materials considered for target fabrication are shown in Table 4.

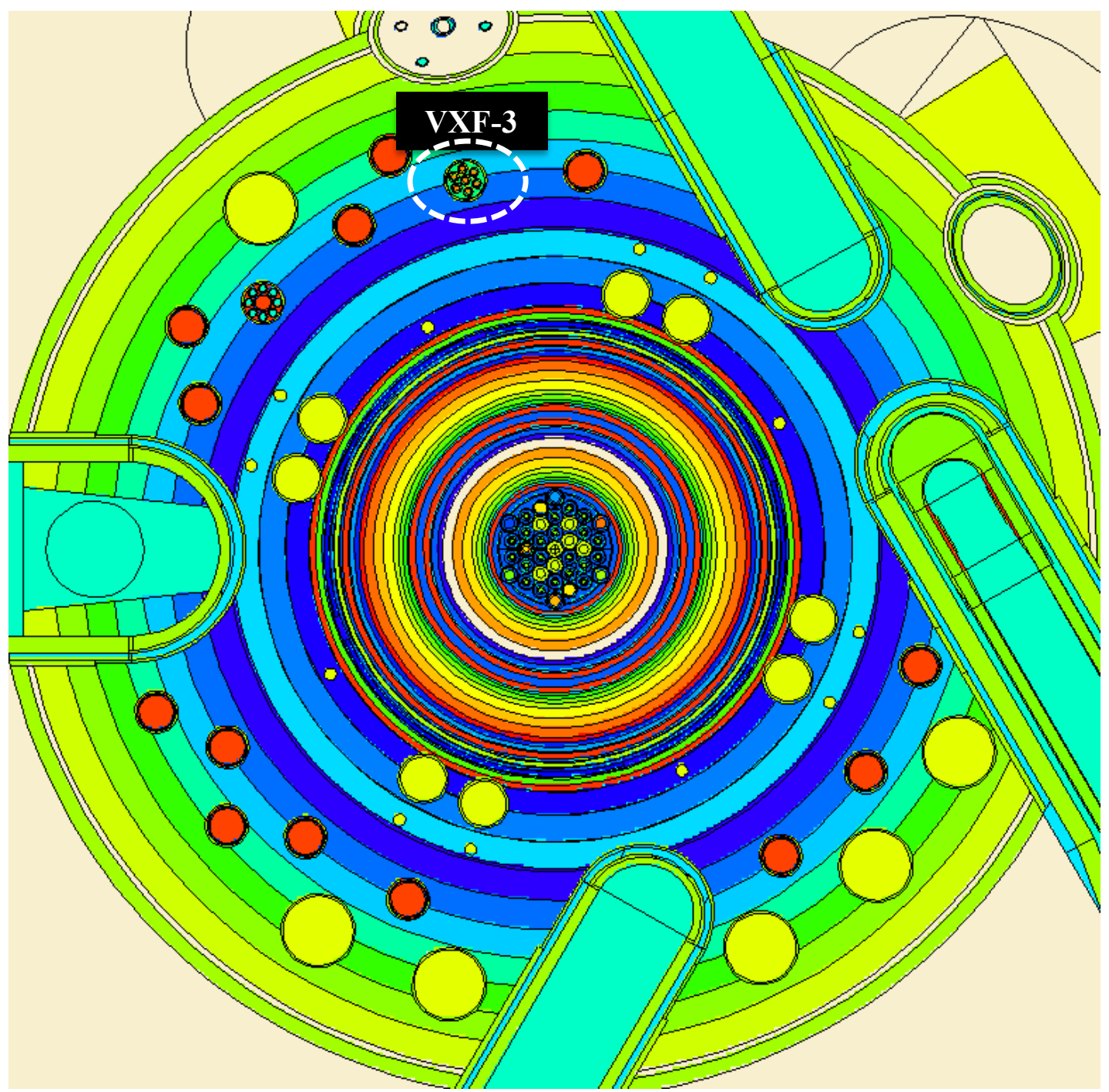

Figure 3. Position of target bundle in HFIR. 


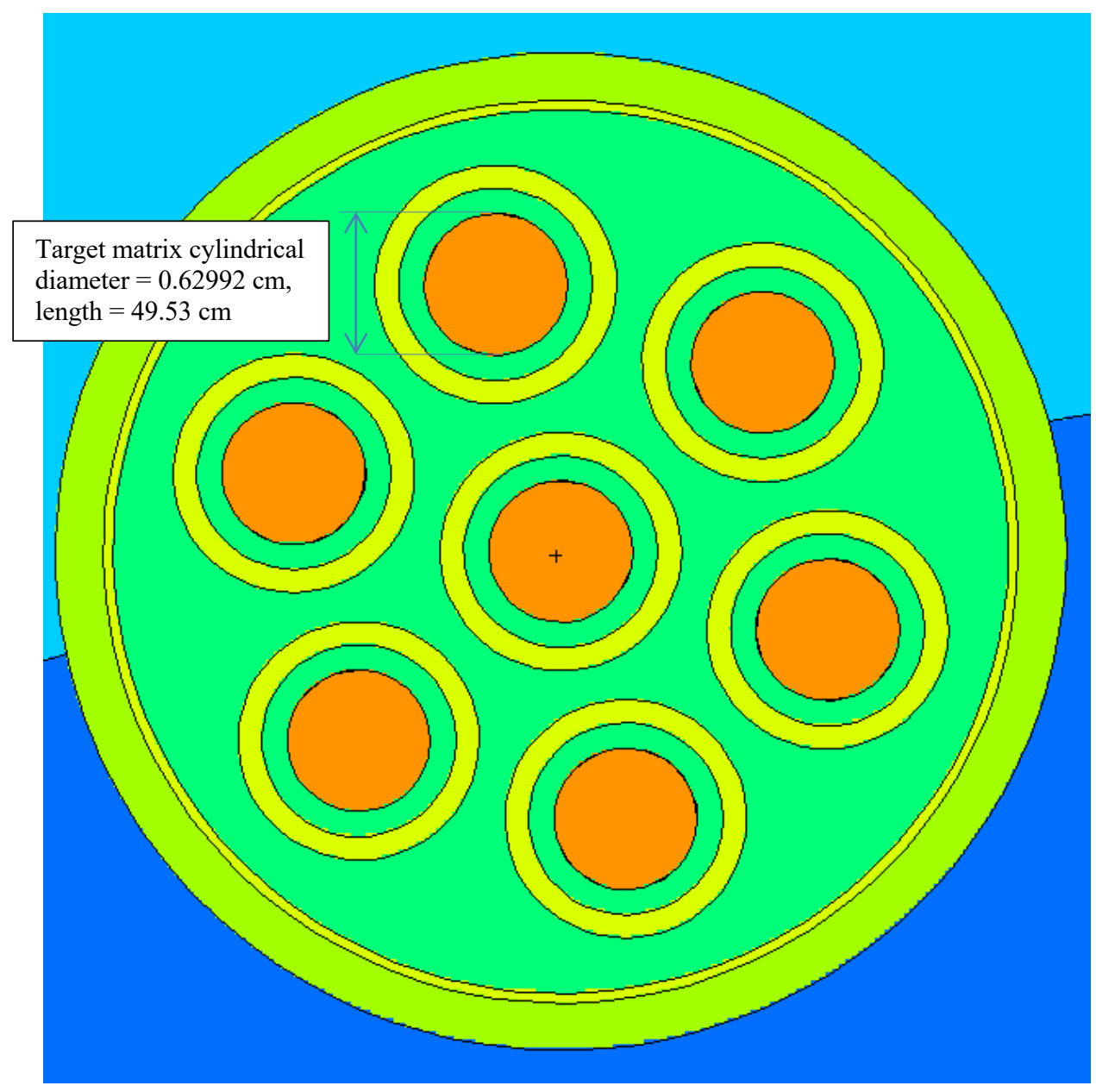

Figure 4. Seven-target-bundle cross section.

Table 4. Alternative target materials considered for benchmarking Pu production calculations

\begin{tabular}{|c|c|c|}
\hline Target material $^{a}$ & $\begin{array}{c}\mathbf{2 5}^{\circ} \mathbf{C} \text { solid } \\
\text { density (g-Np/cc) }\end{array}$ & $\begin{array}{c}\mathbf{6 0 0}^{\circ} \mathbf{C} \text { fluid } \\
\text { density (g-Np/cc) }\end{array}$ \\
\hline $\mathrm{NpF}_{3}$ & 7.3 & - \\
\hline $\mathrm{NpF}_{4}$ & 5.2 & - \\
\hline $\mathrm{NpCl}_{3}$ & 3.7 & - \\
\hline $\mathrm{NpCl}_{3}{ }^{b}$ & 3.7 & - \\
\hline $\mathrm{NpCl}_{4}$ & - & 2.2 \\
\hline $\mathrm{NpCl}_{4}{ }^{b}$ & - & 2.2 \\
\hline${ }^{7} \mathrm{LiF}-\mathrm{NaF}_{-} \mathrm{NpF}_{4}$ & - & 2.91 \\
\hline
\end{tabular}

${ }^{a}$ Cermet target-matrix density is $1.98 \mathrm{~g}-\mathrm{Np} / \mathrm{cc}$, oxide pellet density is $9.8 \mathrm{~g}-\mathrm{Np} / \mathrm{cc}$.

${ }^{b}$ Enriched in ${ }^{37} \mathrm{Cl}$.

The yields of the major Pu isotopes in each of the considered target matrices are shown in Table 4, and the $\mathrm{Pu}$ vector in relative weight percent is shown in Table 5. Yields are calculated at 30 days postbombardment to allow for decay of short half-life isotopes such as ${ }^{238} \mathrm{~Np}$. The predictions in Table 5 
for target yield may not include reductions due to target self-shielding that arise from configurations in the reactor that are not included in our model.

Table 5. Plutonium yields for current and alternative target materials

\begin{tabular}{|l|c|c|c|c|c|c|c|c|c|}
\hline \multirow{2}{*}{ Isotope } & \multicolumn{7}{|c|}{ Isotope yield (g) by target matrix for the seven target bundle } \\
\cline { 2 - 11 } & $\mathbf{C e r m e t}$ & $\mathbf{N p O}_{\mathbf{2}}$ & $\mathbf{N p F}_{\mathbf{3}}$ & $\mathbf{N p F _ { 4 }}$ & $\mathbf{N p C l}_{\mathbf{3}}$ & $\mathbf{N p C l}_{\mathbf{3}}{ }^{a}$ & $\mathbf{N p C l}_{\mathbf{4}}$ & $\mathbf{N p C l}_{\mathbf{4}}{ }^{a}$ & $\begin{array}{c}{ }^{\mathbf{7}} \mathbf{L}-\mathbf{N a F}_{-} \\
\mathbf{N p F}_{4}\end{array}$ \\
\hline${ }^{236} \mathrm{Pu}$ & $2.10 \mathrm{E}-05$ & $7.56 \mathrm{E}-05$ & $6.22 \mathrm{E}-05$ & $4.63 \mathrm{E}-05$ & $2.94 \mathrm{E}-05$ & $3.65 \mathrm{E}-05$ & $2.30 \mathrm{E}-05$ & $3.02 \mathrm{E}-05$ & $2.20 \mathrm{E}-05$ \\
\hline${ }^{238} \mathrm{Pu}$ & $1.98 \mathrm{E}+01$ & $3.53 \mathrm{E}+01$ & $3.37 \mathrm{E}+01$ & $3.03 \mathrm{E}+01$ & $2.09 \mathrm{E}+01$ & $2.71 \mathrm{E}+01$ & $1.83 \mathrm{E}+01$ & $2.46 \mathrm{E}+01$ & $1.98 \mathrm{E}+01$ \\
\hline${ }^{239} \mathrm{Pu}$ & $1.94 \mathrm{E}+00$ & $1.26 \mathrm{E}+00$ & $1.47 \mathrm{E}+00$ & $1.69 \mathrm{E}+00$ & $1.05 \mathrm{E}+00$ & $1.82 \mathrm{E}+00$ & $9.83 \mathrm{E}-01$ & $1.88 \mathrm{E}+00$ & $1.42 \mathrm{E}+00$ \\
\hline${ }^{240} \mathrm{Pu}$ & $1.69 \mathrm{E}-01$ & $4.39 \mathrm{E}-02$ & $6.04 \mathrm{E}-02$ & $8.64 \mathrm{E}-02$ & $4.86 \mathrm{E}-02$ & $1.11 \mathrm{E}-01$ & $4.88 \mathrm{E}-02$ & $1.29 \mathrm{E}-01$ & $9.14 \mathrm{E}-02$ \\
\hline${ }^{241} \mathrm{Pu}$ & $2.10 \mathrm{E}-02$ & $3.64 \mathrm{E}-03$ & $5.40 \mathrm{E}-03$ & $8.44 \mathrm{E}-03$ & $4.61 \mathrm{E}-03$ & $1.18 \mathrm{E}-02$ & $4.77 \mathrm{E}-03$ & $1.43 \mathrm{E}-02$ & $9.83 \mathrm{E}-03$ \\
\hline
\end{tabular}

${ }^{a}$ Enriched in ${ }^{37} \mathrm{Cl}$.

Table 6. Plutonium vector by weight percent for current and alternative target materials

\begin{tabular}{|c|c|c|c|c|c|c|c|c|c|}
\hline \multirow[b]{2}{*}{ Isotope } & \multicolumn{9}{|c|}{ Isotope yield (wt\% of $\mathrm{Pu}$ ) by target matrix } \\
\hline & $\begin{array}{c}\text { Cermet } \\
(\%)\end{array}$ & $\begin{array}{c}\mathrm{NpO}_{2} \\
(\%)\end{array}$ & $\begin{array}{c}\mathrm{NpF}_{3} \\
(\%)\end{array}$ & $\begin{array}{c}\mathrm{NpF}_{4} \\
(\%)\end{array}$ & $\begin{array}{c}\mathrm{NpCl}_{3} \\
(\%)\end{array}$ & $\begin{array}{c}\mathrm{NpCl}_{3}{ }^{a} \\
(\%)\end{array}$ & $\begin{array}{c}\mathrm{NpCl}_{4} \\
(\%)\end{array}$ & $\begin{array}{c}\mathrm{NpCl}_{4}{ }^{a} \\
(\%)\end{array}$ & $\begin{array}{c}{ }^{7} \mathrm{Li}-\mathrm{NaF}-\mathrm{NpF}_{4} \\
(\%)\end{array}$ \\
\hline${ }^{236} \mathrm{Pu}$ & 0.00 & 0.00 & 0.00 & 0.00 & 0.00 & 0.00 & 0.00 & 0.00 & 0.00 \\
\hline${ }^{238} \mathrm{Pu}$ & 90.26 & 96.42 & 95.65 & 94.43 & 95.01 & 93.28 & 94.63 & 92.39 & 92.85 \\
\hline${ }^{239} \mathrm{Pu}$ & 8.87 & 3.45 & 4.16 & 5.27 & 4.75 & 6.29 & 5.09 & 7.07 & 6.67 \\
\hline${ }^{240} \mathrm{Pu}$ & 0.77 & 0.12 & 0.17 & 0.27 & 0.22 & 0.38 & 0.25 & 0.48 & 0.43 \\
\hline${ }^{241} \mathrm{Pu}$ & 0.10 & 0.01 & 0.02 & 0.03 & 0.02 & 0.04 & 0.02 & 0.05 & 0.05 \\
\hline${ }^{242} \mathrm{Pu}$ & 0.01 & 0.00 & 0.00 & 0.00 & 0.00 & 0.00 & 0.00 & 0.00 & 0.00 \\
\hline
\end{tabular}

${ }^{a}$ Enriched in ${ }^{37} \mathrm{Cl}$.

In Table 4, all of the salt matrix targets, except $\mathrm{NpCl}_{4}$ and ${ }^{7} \mathrm{Li}-\mathrm{NaF}-\mathrm{NpF}_{4}$ result in a higher yield of ${ }^{238} \mathrm{Pu}$ than the currently used $\mathrm{NpO}_{2}$ cermet targets, but none result in a higher yield than the in development pure oxide targets. This highest performing salt matrix targets in terms of total ${ }^{238} \mathrm{Pu}$ yield are the $\mathrm{NpF}_{3}$ and $\mathrm{NpF}_{4}$ targets, followed by the ${ }^{37} \mathrm{Cl}$-enriched $\mathrm{NpCl}_{3}$ and $\mathrm{NpCl}_{4}$ targets. The yields of the major $\mathrm{Pu}$ isotopes in each of the considered target matrices is shown in Table 5. Yields are calculated at 30 days postbombardment to allow for decay of short half-life isotopes such as ${ }^{238} \mathrm{~Np}$. Table 5 shows again, all salt matrix material outperforms the $\mathrm{NpO}_{2}$ cermet in terms of ${ }^{238} \mathrm{Pu}$ purity, but none outperform pure $\mathrm{NpO}_{2}$.

However, other metrics are of interest for production of ${ }^{238} \mathrm{Pu}$ beyond just the gross target yield. Both $\mathrm{Np}$ utilization and conversion efficiency are important. We define the "Np utilization" as the amount of ${ }^{238} \mathrm{Pu}$ produced relative to the amount of ${ }^{237} \mathrm{~Np}$ loaded into the target. We define "Np conversion efficiency" as the amount of ${ }^{238} \mathrm{Pu}$ produced relative to how much ${ }^{237} \mathrm{~Np}$ is consumed during irradiation. Both of these measures influence the overall efficiency of production, and a more efficient production process will result in cost savings both in target fabrication and post-irradiation isolation of the ${ }^{238} \mathrm{Pu}$. The production metrics based on our simulations of the various irradiation matrices are shown in Table 7. 
Table 7. Utilization and efficiency of utilization of $\mathrm{Np}$ for current and alternative target materials

\begin{tabular}{|l|c|c|}
\hline Target Material & $\begin{array}{c}\text { Np Utilization } \\
\text { (\%) }\end{array}$ & $\begin{array}{c}\text { Np Conversion }_{\text {Efficiency }^{c}} \\
\text { (\%) }\end{array}$ \\
\hline Cermet & 9.34 & 83.47 \\
\hline $\mathrm{NpO}_{2}$ & 3.59 & 93.52 \\
\hline $\mathrm{NpF}_{3}$ & 4.38 & 98.04 \\
\hline $\mathrm{NpF}_{4}$ & 5.56 & 94.22 \\
\hline $\mathrm{NpCl}_{3}$ & 5.14 & 95.85 \\
\hline $\mathrm{NpCl}_{3}{ }^{a}$ & 6.64 & 91.12 \\
\hline $\mathrm{NpCl}_{4}$ & 5.55 & 94.69 \\
\hline $\mathrm{NpCl}_{4}{ }^{a}$ & 7.47 & 88.87 \\
\hline${ }^{7} \mathrm{LiF}_{-} \mathrm{NaF}-\mathrm{NpF}_{4}$ & 7.09 & 86.87 \\
\hline
\end{tabular}

${ }^{a}$ Enriched in ${ }^{37} \mathrm{Cl}$.

${ }^{b}$ Calculated grams yield of ${ }^{238} \mathrm{Pu}$ per gram ${ }^{237} \mathrm{~Np}$ loaded.

${ }^{c}$ Calculated grams yield of ${ }^{238} \mathrm{Pu}$ per gram ${ }^{237} \mathrm{~Np}$ lost (transmuted) during irradiation.

In Table 7, each of the salt matrix options outperforms the pure $\mathrm{NpO}_{2}$ target in terms of ${ }^{237} \mathrm{~Np}$ utilization but underperforms the cermet target. The results are mixed for $\mathrm{Np}$ conversion efficiency. In this scenario, all the halide matrices outperform the cermet target, and neptunium fluorides $\left(\mathrm{NpF}_{3}, \mathrm{NpF}_{4}\right)$, and neptunium chlorides $\left(\mathrm{NpCl}_{3}, \mathrm{NpCl}_{4}\right)$ utilizing natural chlorine outperform the pure $\mathrm{NpO}_{2}$ targets. The effect of $\mathrm{Np}$ density on the ${ }^{238} \mathrm{Pu}$ yield and $\mathrm{Np}$ utilization can be seen clearly in the trends displayed in the Figures 5 and 6 below. 


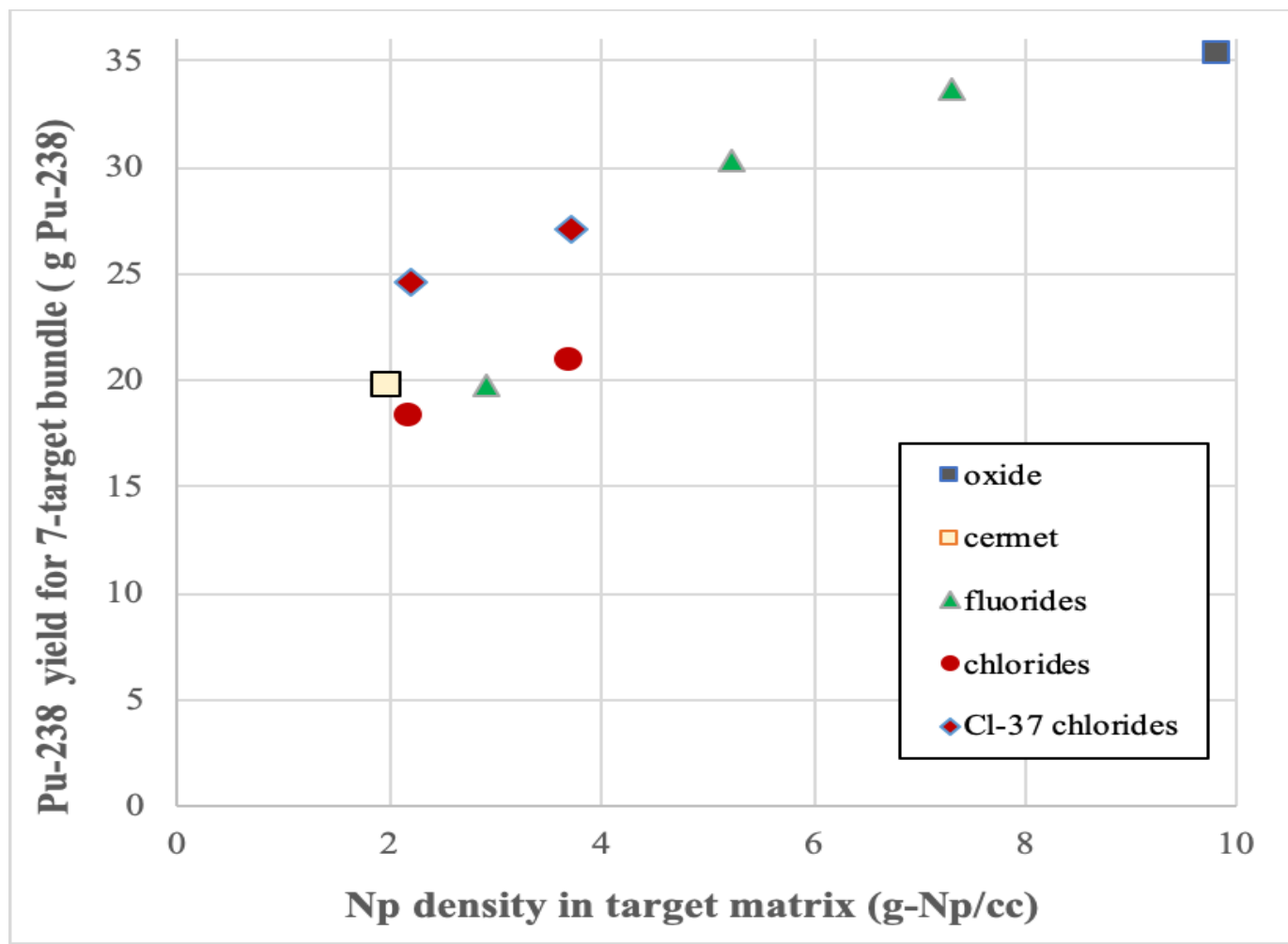

Figure 5. Trend of ${ }^{238} \mathrm{Pu}$ yield with neptunium density in target matrix.

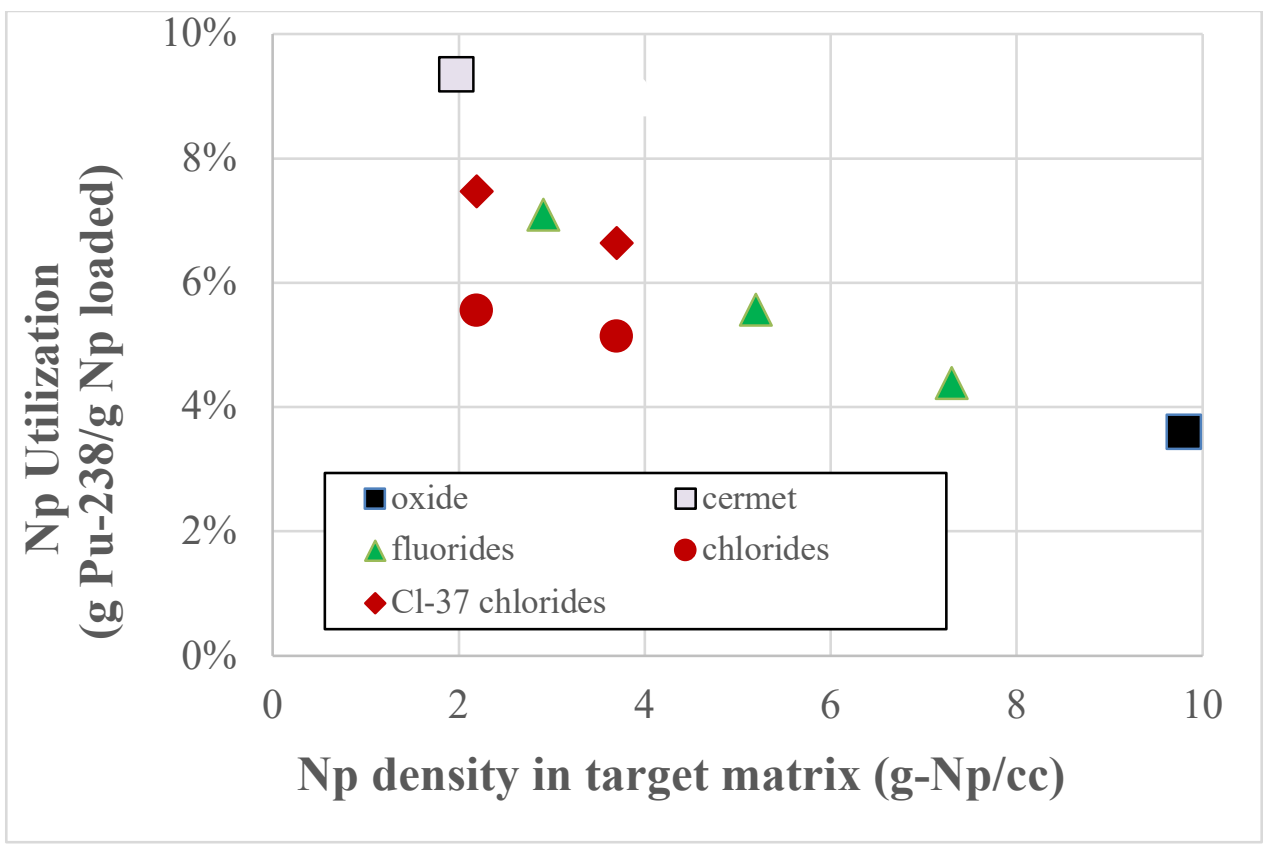

Figure 6. Trend of neptunium utilization with neptunium density in target matrix.

In addition to assessing the performance of alternative target materials, additional calculations were performed to examine the effects of cycling ${ }^{237} \mathrm{~Np}$ in and out of the irradiation volume. For this assessment, a problem specific ORIGEN-S cross section library was produced using the average cross section for ${ }^{237} \mathrm{~Np}$ capture in the current ${ }^{238} \mathrm{Pu}$ production cermet targets and using the infinitely dilute cross 
sections for all other reactions. Transmutation of a nominal $1 \mathrm{~g}$ mass of ${ }^{237} \mathrm{~Np}$ was simulated for a variety of timings. The material was subject to the average neutron flux in the VXF-3 position while the material was within the active region of the vessel, but the material was not subject to neutron flux while the material was not be within the active region of the vessel. Irradiation was simulated for two 25 day cycles as in previous assessments.

Assuming the active region of the vessel will be continuously occupied with target material from different target elements, the amount of ${ }^{238} \mathrm{Pu}$ that would be produced during the irradiation can be scaled based on the ratio of the time of a single element in the active region to the total cycle time. For example, for the case of an element occupancy of 2.5 days in the active region of the reactor vessel followed by 2.5 days outside of the active region, carried out in this manner five times for a total of 25 days, that particular element would be in the vessel for $50 \%$ of the cycle time. Therefore, twice as much material could be irradiated in this position of the reactor vessel, and the total yield would be twice the calculated value for a single element. The $\mathrm{Np}$ utilization and conversion efficiency for various timings and continuous occupation of the active region is shown in Table 8, along with the total yield of ${ }^{238} \mathrm{Pu}$ (expressed as ${ }^{238} \mathrm{Pu}$ potential (relative) in Table 8).

Table 8. Plutonium yield potential with cycling through active region of the reactor vessel

\begin{tabular}{|c|c|c|c|c|}
\hline $\begin{array}{l}\text { Days in active } \\
\text { region }\end{array}$ & $\begin{array}{c}\text { Days out of } \\
\text { active region }\end{array}$ & $\begin{array}{c}\text { Np Utilization } \\
(\%)\end{array}$ & $\begin{array}{c}\text { Np Conversion } \\
\text { Efficiency }^{b} \\
(\%)\end{array}$ & $\begin{array}{l}{ }^{238} \text { Pu potential } \\
{\text { (relative })^{c}}^{c}\end{array}$ \\
\hline 25 & 0 & 8.36 & 76.16 & 1.00 \\
\hline 1 & 1 & 4.91 & 83.65 & 1.13 \\
\hline 2.5 & 2.5 & 4.89 & 86.69 & 1.17 \\
\hline 5 & 5 & 5.42 & 80.48 & 1.08 \\
\hline 5 & 2.5 & 6.31 & 80.81 & 1.08 \\
\hline 7.5 & 2.5 & 7.00 & 78.80 & 1.05 \\
\hline 2.5 & 5 & 3.78 & 83.26 & 1.13 \\
\hline
\end{tabular}

${ }^{a}$ Calculated grams yield of ${ }^{238} \mathrm{Pu}$ per gram ${ }^{237} \mathrm{~Np}$ loaded

${ }^{b}$ Calculated grams yield of ${ }^{238} \mathrm{Pu}$ per gram ${ }^{237} \mathrm{~Np}$ lost (transmuted) during irradiation

${ }^{c}{ }^{238} \mathrm{Pu}$ production for cycling target occupation during entire irradiation cycle normalized to stationary target case.

As expected, the neptunium utilization is decreased when the total exposure of the neptunium is decreased. However, the conversion efficiency improved significantly, and when normalized to the exposure time to account for continuous occupation of the active region of the reactor vessel, all of the evaluated cycling timings outperformed the case of no movement through the vessel. The highest performing timing evaluated was 2.5 days in the active region of the reactor vessel, followed by 2.5 days out of the active region of the reactor vessel. For this scenario, the total ${ }^{238} \mathrm{Pu}$ potential increased by $17 \%$ over the relative yield for no material movement, and the conversion efficiency increased from $76 \%$ to $87 \%$. This indicates that the amount of transmuted ${ }^{237} \mathrm{~Np}$, which does not result in ${ }^{238} \mathrm{Pu}$ (primarily by fission of intermediary ${ }^{238} \mathrm{~Np}$ though also due to multiple neutron captures) drops from $24 \%$ to $13 \%$, or a nearly $50 \%$ reduction in relative losses for these simulated scenarios.

The idealized fission-loss fraction given under equilibrium conditions for a constant irradiation can be calculated as

\footnotetext{
$\$$ Private communication from J. Gehin, Oak Ridge National Laboratory, to D. Chandler, Oak Ridge National
} Laboratory May 26, 2013. 


$$
\text { Fission fraction }=\frac{\sigma_{f} \phi}{\sigma_{a} \phi+\lambda} \sim 8 \%
$$

for the following conditions:

$$
\begin{aligned}
& \sigma_{f}=\text { HFIR spectrum single group fission cross section for }{ }^{238} \mathrm{~Np}=1,087 \text { barns } \\
& \sigma_{\mathrm{a}}=\text { HFIR spectrum single group absorption cross section for }{ }^{237} \mathrm{~Np}=176 \text { barns } \\
& \phi=\text { HFIR spectrum single group cycle averaged flux }=2.9 \times 10^{14} \mathrm{n} / \mathrm{cm}^{2}-\mathrm{s} \\
& \lambda=\text { decay constant of }{ }^{238} \mathrm{~Np}=3.79 \times 10^{-6} \mathrm{~s}^{-1}
\end{aligned}
$$

In practice, the fission loss fraction is greater than this theoretical value because the effective absorption cross section for ${ }^{237} \mathrm{~Np}$ is significantly reduced by self-shielding effects. Additional losses occur due to absorption in ${ }^{238} \mathrm{Pu}$.

For other limiting conditions and assumptions, the idealized fission loss fraction can rise to about $20 \%$ for HFIR. We did not find any conditions approaching the $85 \%$ fission loss estimate cited in the 2011 Howe paper (38).

The results in this report are consistent with the following interpretations:

- Even though ${ }^{238} \mathrm{~Np}$ has a very large fission cross section and acts as a neutron sink, the primary limit on Pu-yield in dense targets arises from the self-shielding effect of ${ }^{237} \mathrm{~Np}$ itself. Greater Np utilization (grams ${ }^{238} \mathrm{Pu}$ gram produced per gram of $\mathrm{Np}$ in the target) is achieved in less dense targets that spread the target isotope throughout the target volume.

- There is a considerable improvement $(\sim 30 \%)$ in $\mathrm{Pu}$ yields for targets using enriched ${ }^{37} \mathrm{Cl}$ rather than natural chlorine.

\section{REQUIREMENTS AND CONCEPTS FOR THERMAL CONTROL OF TARGETS}

A preliminary design of an irradiation capsule is a serious undertaking and far beyond the scope of this report. However, as a first step toward a preliminary design, we outline top-level requirements a capsule design will need to satisfy and highlight the additional information, modeling and simulation, and preliminary experiments that will be needed. Some basic design concepts that could be used to address the specific design challenges posed by molten salt targets are also highlighted to assist future studies.

Irradiation capsules must be designed to operate within the reactor safety envelope and must be practical and safe to fabricate, install, and remove, as well as support isotope recovery. Primary attention is typically given to safe operation in the reactor as this requirement is paramount and often the most stringent with regard to design. Retention of radioactivity within the capsule boundary to prevent any release to the coolant, pool, or building ventilation is required.

The capsule must be maintained within bounds of temperature, pressure, stress, and potential degradation mechanisms (corrosion, irradiation materials damage) that maintain its ability to function and retain the target radioactivity. Capsule designs are supported by nuclear, thermal, structural, and thermodynamic modeling as well as out-of-pile testing. Often, these design limits are associated with the highest local temperature that can be achieved (especially during transients), the highest burnup of the target material, or the highest exposure level of the container material to neutrons. For molten salts, there is also a potential for a low-temperature effect associated with the radiolysis of the solid salt either in the reactor flux or due to the beta-gamma radiation contained within the salt itself. Thus, the capsule may need to 
maintain the target material at a suitably high temperature to avoid unwanted radiolysis and generation of high pressures of halogen gas and reduced species in the salt. This control may need to be exercised not only during irradiation, but also when the reactor is shutdown or during transfer and prior to target processing. The need to understand the radiolysis behavior of the solid salt cannot be overlooked, and operational limits must be defined.

There are a number of well-established tools such as gas-gaps and gamma-heating features that can be applied to address thermal control of targets, and there is no need to highlight these in this report. However, highlighting special problems or aspects associated with salt targets is worthwhile. Special problems with these targets include

- salt radiolysis (as described in the preceding paragraph),

- thermal stresses and induced stress due to thermal expansion of solid salt or confined molten salt, and

- the opportunity to remove salts as a fluid or harvest product-rich solid deposits on a substrate without the need to remove the entire capsule.

These issues might be addressed by the following design features:

- Salt radiolysis:

- Systems to maintain the salt above threshold temperature for radiolysis

- An internal "getter" such as a salt soluble reductant to counteract radiolysis (consume and fix halogen gas)

○ An external "getter" to consume and fix radiolytic halogen gas

- Salt-induced stresses:

- A robust capsule design which can withstand all the potential stresses without any loss of function

- Independent capsule heating element to control salt temperature to melt the salt in a controlled fashion and prevent freezing

- Expedited material transfer without capsule removal (i.e., direct reuse of capsule):

- A capability to insert and withdraw collection surfaces or salts

- Various concepts could be developed-MSRE sampler/enricher design and operating experience should be reviewed as a first step (39)

Many potential designs could address these issues, and the degrees of freedom that are afforded by modern modeling, materials, measurement, and fabrication capabilities is very large; therefore, we expect that practical systems can be devised and implemented. We expect new solutions to be devised that challenge convention. For example, it has long been judged that solid salts have such low thermal conductivities they cannot be used for high-heat flux applications (40), but we might expect that molten salts could be infused within a conductive network (e.g., carbon foam) and that heat transfer path lengths could be established to maintain the composite matrix of salt and network material such that salt melting point is not exceeded.

In most cases, the ability to design and operate the capsule is unlikely to be a limiting factor in the decision to pursue a salt matrix for isotope production. However, these capsule designs will require an array of experts to work together as a team in a dedicated fashion and steady sponsor support for many years. In this regard, the case for the entire production cycle including irradiation, transport, processing, recycle, waste management, and distribution is needed to support the commitment to this research and development path. 


\section{DEVELOPMENT PATHS FOR NEW TARGETS AND PROCESSES}

This report highlights and ranks the various factors and developments that are needed to support the creation of salt matrix irradiation targets for isotope production. Foremost among these needs is a clear understanding of which applications benefit the most from a salt matrix target and how these applications can be pursued in a strategic manner that recognizes and integrates the various technical advances and capabilities. Some research and development elements can be pursued at a smaller scale to establish proof-of-principle, some (perhaps thermophysical properties, radiolysis studies) can build upon contributions from ongoing work in MSR programs, but some aspects of a particular isotope production pathway will be application specific, such as

- a detailed understanding of noble metal fission product chemical behavior and design for removal of collectors from the target (for ${ }^{99}$ Mo production),

- the ability to process irradiated $\mathrm{Np}$-salt targets in an integrated fashion solely by chloride ionexchange operations, and the recycle of $\mathrm{Np}$ back into a form for the salt target, and

- the ability to process transplutonium salt targets in an all-chloride flowsheet as was initially planned for the HFIR-REDC complex in the 1960s.

Although these particular aspects of a production technology pose distinct challenges, elements of the design and testing capabilities for many capsules will be similar and will benefit from establishing a target for any of the isotopes under consideration for production.

\section{REFERENCES}

1. D. B. Trauger, Some Major Fuel-Irradiation Test Facilities of the Oak Ridge National Laboratory, Oak Ridge National Laboratory, Report ORNL-3574, pp. 80-84, 1964.

https://www.osti.gov/biblio/4043196

2. W. R. Grimes, W. R. , Radiation Chemistry of MSR System, Oak Ridge National Laboratory, Report ORNL-TM-500, p. 51, 1963. https://www.osti.gov/servlets/purl/12780864

3. W. R. Grimes, Materials Problems in Molten Salt Reactors in [book auth.] M.T. Simnad and L.R. Zumwalt. Materials and Fuels for High-Temperature Nuclear Energy Applications. Cambridge, MA: MIT Press, 1962.

4. R. B. Briggs, Molten-Salt Reactor Program Semiannual Progress Report for Period Ending August 31, 1962, pp. viii, 100-115, Oak Ridge National Laboratory, Report ORNL-3369, 1962. https://www.osti.gov/src/fulltext/4729477

5. J. McDuffee et al., Evaluation of Flowing Salt Irradiation Facilities with High Neutron Flux. Oak Ridge National Laboratory, Report ORNL/TM-2018/954, p. 37, 2018. https://info.ornl.gov/sites/publications/Files/Pub115045.pdf

6. V. D. Braiko et al., "Tests on Setup with Natural Circulation of $\mathrm{LiF}_{-} \mathrm{BeF}_{2}-\mathrm{UF}_{4}$ Liquid-Salt Fuel," Soviet Atomic Energy (69), pp. 817-821, October 1990.

7. V. D. Braiko et al., KURS-2 reactor loop with a molten salt fuel. Kurchatov Institute Report, IAE4450/4, p. 27, 1987. 
8. H. C. Savage, Operation of Molten-Salt Convection Loops in the ORR, Oak Ridge National Laboratory, Report ORNL-TM-1960, p. 43, 1967. https://www.osti.gov/src/fulltext/4580057

9. David Carpenter, "Tritium Production and Partitioning from the Irradiation of Lithium-Beryllium Fluoride Salt,” Fusion Science and Technology (71), pp. 549-554, May 2017.

10. David Carpenter, "Fluoride Salt High-Temperature Reactor Materials Irradiation Test at the MIT Research Reactor," Proceedings of ICAPP 2014. Paper 14285, 2014.

11. P. R. Hania, "MSR Irradiation Program at NRG Petten," MSR Workshop 2018 Presentation: Oak Ridge, TN, October 4, 2018. https://msrworkshop.ornl.gov/wp-content/uploads/2018/10/MSR2018presentation-Hania-NRGEU.pdf.

12. J. McDuffee, Design and Irradiation of a Molten Salt Corrosion Experiment in The Ohio State University Research Reactor, Oak Ridge National Laboratory, Report ORNL/TM-2018/1005, p. 26, 2018. https://info.ornl.gov/sites/publications/Files/Pub115045.pdf

13. C. A. Rohrmann, Radioistopic Heat Sources. Hanford Atomic Products Operation Report HW76323, p. 60, 1963. https://www.osti.gov/servlets/purl/5712006

14. National Research Council, Medical Isotope Production Without Highly Enriched Uranium, National Academies Press, p. 25, 2009. https://www.ncbi.nlm.nih.gov/books/NBK215149/pdf/Bookshelf_NBK215149.pdf

15. J. M. Chandler and R. B. Lindauer, "Preparation and Processing of MSRE Fuel" in [ed.] P. Chiotti: Nuclear Metallurgy: Symposium on Reprocessing of Nuclear Fuels (15), pp. 97-120. US AEC Division of Technical Information, CONF-69080, 1970.

16. R. B. Lindauer, Processing of the MSRE Flush and Fuel Salt, Oak Ridge National Laboratory, Report ORNL-TM-2578, p. 79, 1969. https://www.osti.gov/src/fulltext/4781475

17. R. J. Kedl, The Migration of a Class of Fission Products in the MSRE, Oak Ridge National Laboratory, Report ORNL-TM-3884, 1973. https://www.osti.gov/src/fulltext/4471292

18. E. L. Compere et al., Fission Product Behavior in the MSRE. Oak Ridge National Laboratory, Report ORNL-4865, 1975. https://technicalreports.ornl.gov/1975/3445605698493.pdf

19. A. V. Zagnitko and D. Yu Chuvilin, "Removal of Nanoaerosol During the Bubbling of the Salt Melt of Beryllium and Lithium Fluorides for the Preparation of Reactor Radioisotopes," Russian Journal of Physical Chemistry A, Vol. 84, pp. 1009-1014, 2010.

20. D. Yu. Chuvilin and V. A. Zagryadskii, "New Method of Producing ${ }^{99}$ Mo in Molten-Salt Fluoride Fuel," Atomic Energy (107), pp. 185-193, 2009.

21. D. Yu Chuvilin et al., "Low-Waste and Proliferation-Free Production of Medical Radioisotopes in Solution and Molten-Salt Reactors" Radioactive Waste, IntechOpen, 2012. http://www.egeneration.org/wp-content/Repository/Medical_Isotopes/36023.pdf

22. M. N. Stoddard et al., "Numerical analysis of isotope production in molten salt reactors: A case study for Molybdenum-99 production," Annals of Nuclear Energy (129), pp. 56-61, 2019.

23. E. D. Collins and J. E. Bigelow, "Chemical Process Engineering in the Transuranium Processing Plant" paper at the 24th Conference on Remote Systems Technology in Washington DC. November 14-19, 1976, CONF-761101-10. https://www.osti.gov/src/fulltext/7142440

24. V. P. Calkins, Compilation of Various Fusion Methods for the Dissolution of Insoluble Residues, Atomic Energy Commission Report. AECD-4175, 1946. https://digital.library.unt.edu/ark:/67531/metadc173201/ 
25. V. P. Calkins, Dissolution of Uranium Tetrafluoride, Atomic Energy Commission Report. AECD3064, 1949. https://www.osti.gov/src/fulltext/4410857

26. R. B. Briggs, Molten-Salt Reactor Program Semiannual Progress Report for period ending July 31, 1964, p. 320, Oak Ridge National Laboratory Report, ORNL-3708, 1964.

https://technicalreports.ornl.gov/1964/3445600500358.pdf

27. Y. Hirose, and Y. Takashima, "The concept of fuel cycle integrated molten salt reactor for transmuting Pu+MA from spent LWR fuels," Global 2001 international conference on the Back-end of the fuel cycle: From research to solutions, Paris, France, INIS-FR-1269, 2001. https://www.osti.gov/src/fulltext/20267356

28. S. M. Fried, Separation of Neptunium from Plutonium by Chlorination and Sublimation, US Patent 2,860,948, November 18, 1958. https://patents.google.com/patent/US2860948

29. W. R. Grimes et al., Reactor Chemistry Division Annual Progress Report for Period Ending December 31, 1965. pp. 27-29, Oak Ridge National Laboratory, report ORNL-3913. https://www.osti.gov/src/fulltext/4547015

30. H. B. Yang, "Mutual separation of U, Np, Pu and Am with ion exchange resin in chloride media," Proceedings of the 2005 Korean Nuclear Society Spring Meeting, 2005. https://www.kns.org/files/pre paper/18/299\%EC\%96\%91\%ED\%95\%9C\%EB\%B2\%94.pdf

31. J. M. Chilton and J. J. Fardy, "Isolation of Plutonium from Neptunium: Anion Exchange Resin Studies - I, " Journal of Inorganic and Nuclear Chemistry (31), pp.1171-1177, 1969.

32. W. V. Conner and S. G. Procter, Preparation of Highly Pure Neptunium Oxide, Dow Chemical Company Rocky Flats Division, report RFP-1416, 1969. https://www.osti.gov/src/fulltext/4724372

33. I. G. Tananaev and V. I. Dzyubenko, "Anion-Exchange Removal of Plutonium from Neptunium," Soviet Radiochemistry (31, issue 4), pp.462-464, 1989.

34. P. Masset et al., "Thermochemical properties of lanthanides $(\mathrm{Ln}=\mathrm{La}, \mathrm{Nd})$ and actinides $(\mathrm{An}=\mathrm{U}$, $\mathrm{Np}, \mathrm{Pu}, \mathrm{Am}$ ) in the molten LiCl-KCl eutectic," Journal of Nuclear Materials (344), pp. 173-179, 2005.

35. A. V. Bychkov and O. V. Skiba, "Review of Non-aqueous Nuclear Fuel Reprocessing and Separation Methods (View on world experience from Dimitrovgrad)." [book auth.] G. R. Choppin and M. K. Khankhasayev, Chemical Separation Technologies and Related Methods of Nuclear Waste Management, NATO Science Series 2: Environmental Security, volume 53, 1998.

36. W. W. Schultz and G. E. Benedict, Neptunium-237: Production and Recovery. US Atomic Energy Commission, AEC Critical Review Series: TID-25955, 1972.

https://www.osti.gov/src/fulltext/4599712

37. D. Chandler and R. J. Ellis, "Neutronics Simulations of ${ }^{237} \mathrm{~Np}$ Targets to Support Safety-Basis and ${ }^{238} \mathrm{Pu}$ Production Effors at the High Flux Isotope Reactor," paper 5009 presented at Proceedings of Nuclear and Emerging Technologies for Space (NETS), pp. 40-49, 2015. http://anstd.ans.org/wpcontent/uploads/2015/07/Proceedings-of-NETS-2015.pdf

38. S. D. Howe et al., Economical Production of Pu-238, NIAC Phase I Final Report, Center for Space Research (USRA). p. 49, HQ-E-DAA-TN33538, 2011. https://ntrs.nasa.gov/search.jsp? $\mathrm{R}=20160010587$

39. R. B. Gallaher, Operation of the Sampler-Enricher in the Molten Salt Reactor Experiment. Oak Ridge National Laboratory, Report ORNL-TM-3524, 1971. https://www.osti.gov/src/fulltext/4731130 
40. E. S. Bettis et al., "The Aircraft Reactor Experiment-Design and Construction," Nuclear Science and Engineering (2), pp. 806-807, 1957. 
APPENDIX A. 2015 WHITE PAPER ON NON-AQUEOUS PROCESSING AND FISSION-TARGET OPTIONS FOR ${ }^{99}$ MO PRODUCTION 



\section{APPENDIX A. 2015 WHITE PAPER ON NON-AQUEOUS PROCESSING AND FISSION - TARGET OPTIONS FOR ${ }^{99}$ Mo PRODUCTION}

\section{A-1. Abstract/purpose}

This white paper explores new approaches for recovery and production of ${ }^{99}$ Mo by fission. The application of non-aqueous processing approaches to conventional target designs and molten salt target designs for a next generation of production are reviewed and analyzed within the context of present technology. For the new processing and target options, the advantages and disadvantages are defined and development needs are highlighted.

\section{A-2. Background on current technology}

The production of ${ }^{99} \mathrm{Mo}$ ( $66 \mathrm{~h}$ half-life, $470,000 \mathrm{Ci} / \mathrm{g}, \sim 6 \%$ fission yield) by fission is a commercial process with demanding requirements for timely processing and product purity [A-1], as shown in Figure A-1. This "industry" is in reality a laboratory-scale operation. The annual worldwide production of ${ }^{99} \mathrm{Mo}$ is $\sim 10 \mathrm{~g}$ at the end of irradiation (494,000 Ci of 6-day curies) and fissions about $1 \%$ of $40 \mathrm{~kg}$ of ${ }^{235} \mathrm{U}$ in 3,000 kg of target matrix (about 200 targets/week worldwide). In most cases, the unfissioned uranium reports to a waste stream and is not recycled.

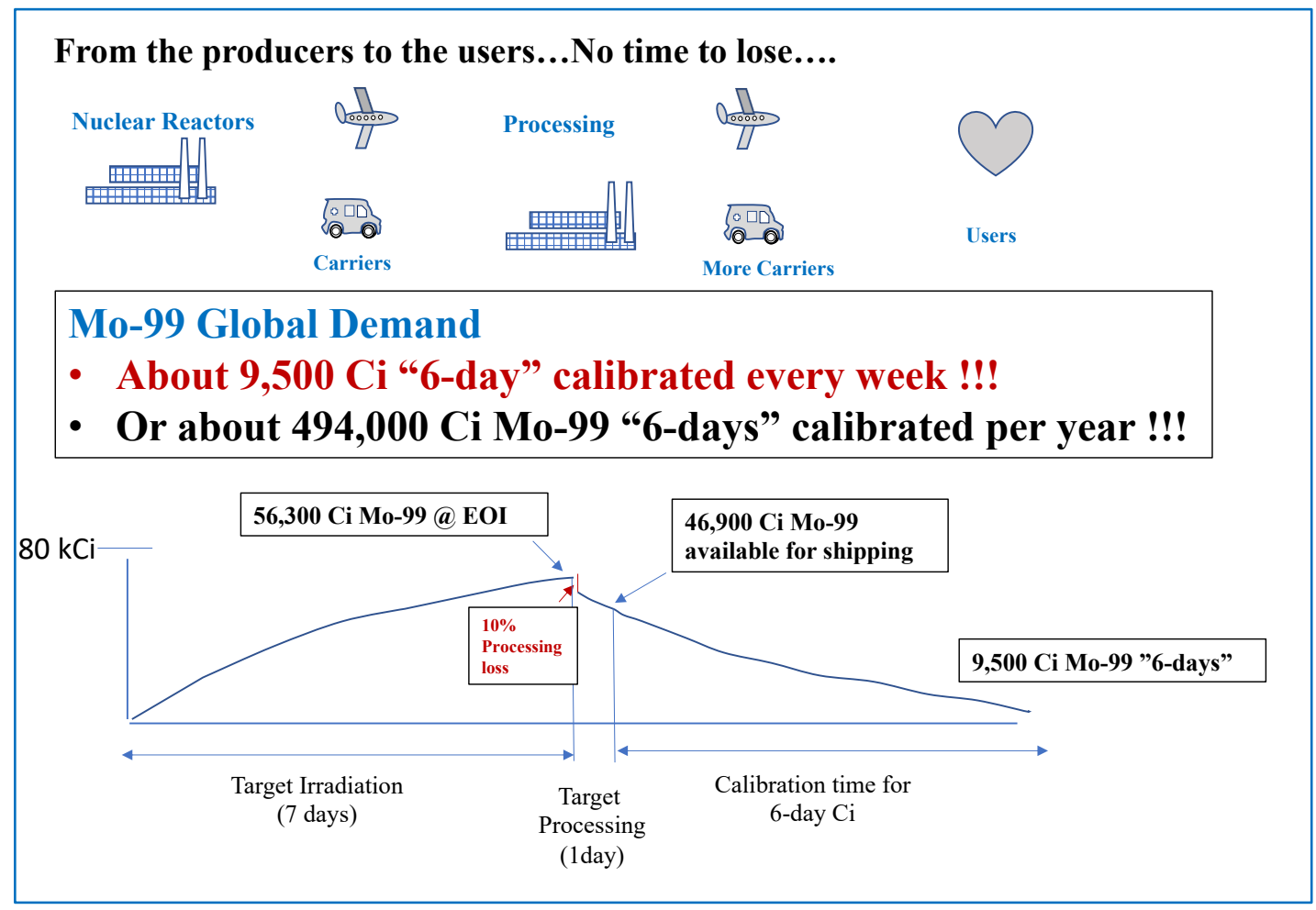

Figure A-1. Molybdneum-99 production timeline: "No time to lose."

Most target designs for ${ }^{99}$ Mo production use aluminum as a cladding and target matrix to transport heat to the reactor coolant. These designs employ cylindrical rods, tubular annuli, and flat-plate geometries as well as aluminum-uranium alloy, aluminide dispersion, uranium metal, and uranium silicide target matrices. There is one older highly enriched uranium target design that uses a stainless steel capsule with $\mathrm{UO}_{2}$ deposited on the interior surface [A-2, A-3]. Representative aluminum-based target designs are depicted in Figure A-2. 


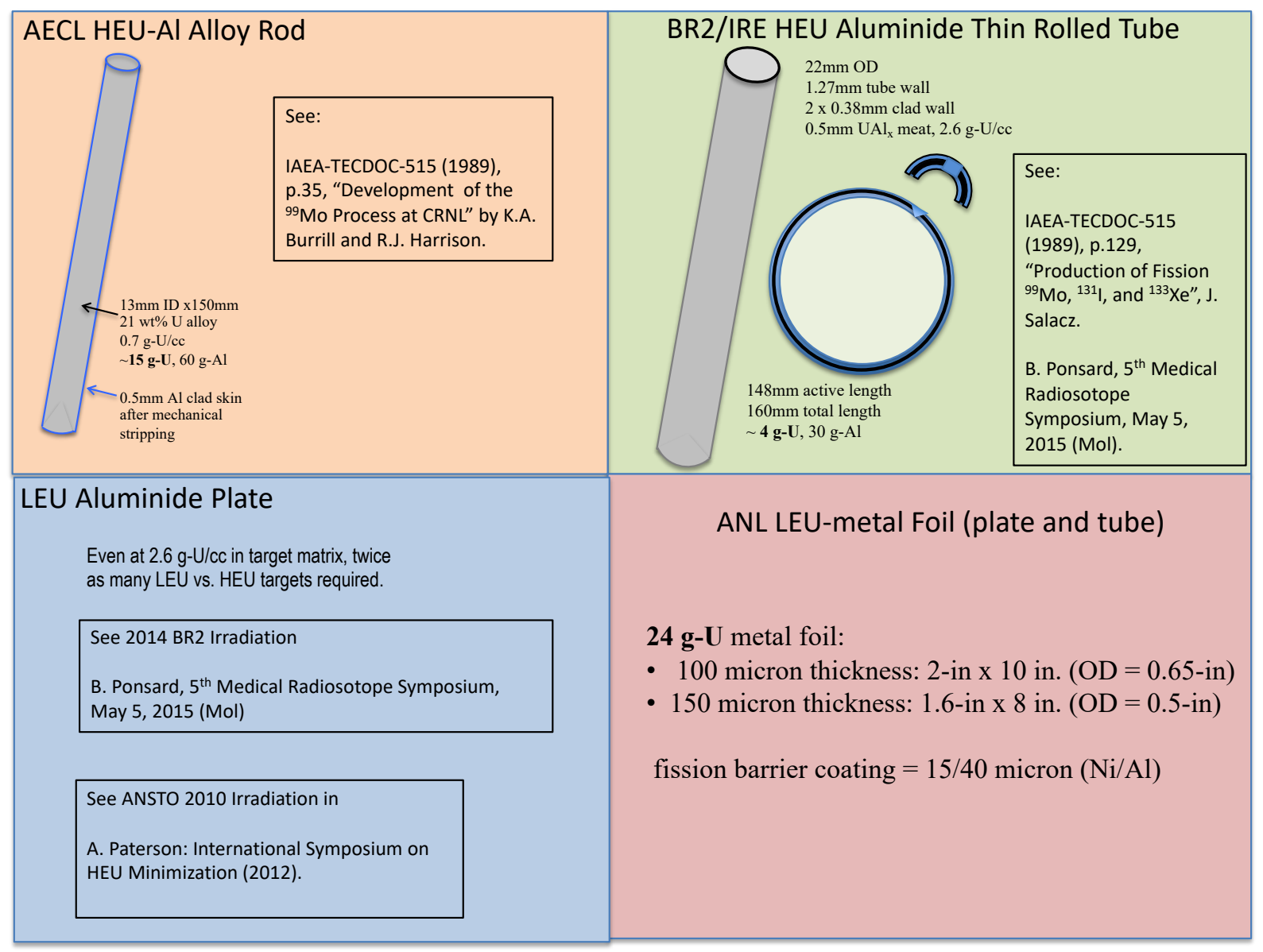

Figure A-2. Characteristic ${ }^{99}$ Mo target designs.

Aqueous processing of aluminum targets for recovery of ${ }^{99}$ Mo is conducted in less than 1 day as shown in Figure A-1. In one family of processes, the target is completely dissolved in $\mathrm{Hg}$-catalyzed nitric acid, and the $\mathrm{U}$ and Mo reside in the solution. In the other family of processes, the target is dissolved in caustic, and uranium and some fission products precipitate while molybdenum and other fission products are recovered in the filtrate. Both types of dissolution are rapid and complete within about 1 hour. Additional high-resolution separations take the balance of the day before a high-purity aqueous concentrate free of organic residues is provided to the generator pharmacy/manufacturer.

\section{A-3. Background on non-aqueous processing}

Starting in the 1950s and culminating in the 1970s, there was intensive worldwide investigation of halide volatility processes for the recovery of $\mathrm{U}$ and $\mathrm{Pu}$ from irradiated fuel. Halide volatility processes were also developed and continue to be used to refine and purify zirconium and uranium feed materials. This review is motivated by the demonstration that extremely high purifications were achieved for uranium recovery and the results for Mo-isolation - while not the motive for prior studies - are promising and relevant for ${ }^{99}$ Mo production.

A wide variety of halide volatility flowsheets were developed for aluminum-based, zirconium-based, and molybdenum-based uranium fuels. Fluoride flowsheets were developed for molten salt processing, whereas chloride and mixed chloride-fluoride flowsheets were developed for fluid-bed processes. In the majority of fluid-bed work $\mathrm{HCl}$ was used for the decladding step and fluorine was used to volatilize 
uranium (and Mo) followed by selective trapping on inorganic sorbents (usually NaF). Molten salt processing also used $\mathrm{NaF}$ traps for uranium recovery.

Halogenation of active metals such as aluminum is highly exothermic. Early on researchers working on direct fluorination of solid-fuel elements with gaseous reagents were not able to regulate the reaction temperature due to the large and non-linear release of chemical reaction heat [A-4, A-5, A-6]. The primary concern was to avoid peak temperatures that would not only chlorinate $\mathrm{Al}$ to volatile $\mathrm{AlCl}_{3}$, but also would convert uranium to somewhat volatile $\mathrm{UCl}_{4}$ (rather than nonvolatile $\mathrm{UCl}_{3}$ ) and volatilize other fission products. This concern led to the use of interhalogen liquid, molten salt, or fluidized bed reactors to directly carry away the heat and regulate the rate of reaction.

Multiple laboratories in different countries demonstrated that $\mathrm{HCl}$ effectively removes aluminum and zirconium cladding in a fluidized bed without the need to disassemble the fuel, and that $\mathrm{UF}_{6}$ can be isolated in the subsequent fluid-bed fluorination as a high purity material and with high uranium recovery rates. Similar conclusions attend the molten salt fluoride volatility flowsheet that entails HF dissolution of the entire fuel element followed by salt fluorination to recover $\mathrm{UF}_{6}$. For both flowsheets, a network of controlled temperature $\mathrm{NaF}$ adsorption beds provide for near quantitative and high purity recovery of the volatile hexafluorides of uranium and molybdenum. The results of the fluid-bed work are summarized in Figures A-3 through A-5 [A-7].

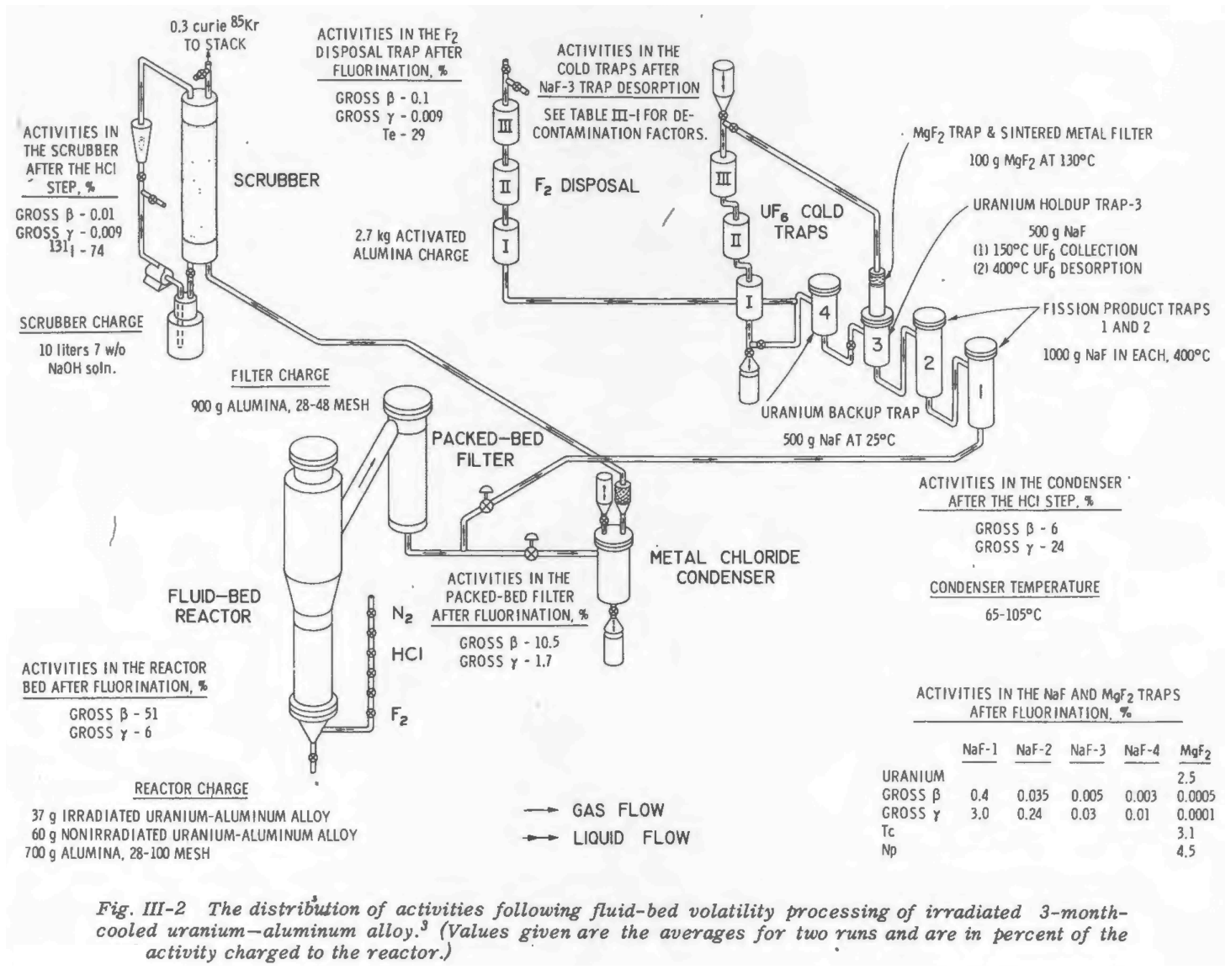

Figure A-3. Fluid-bed volatility processing of 3 month cooled uranium alloy fuel. 


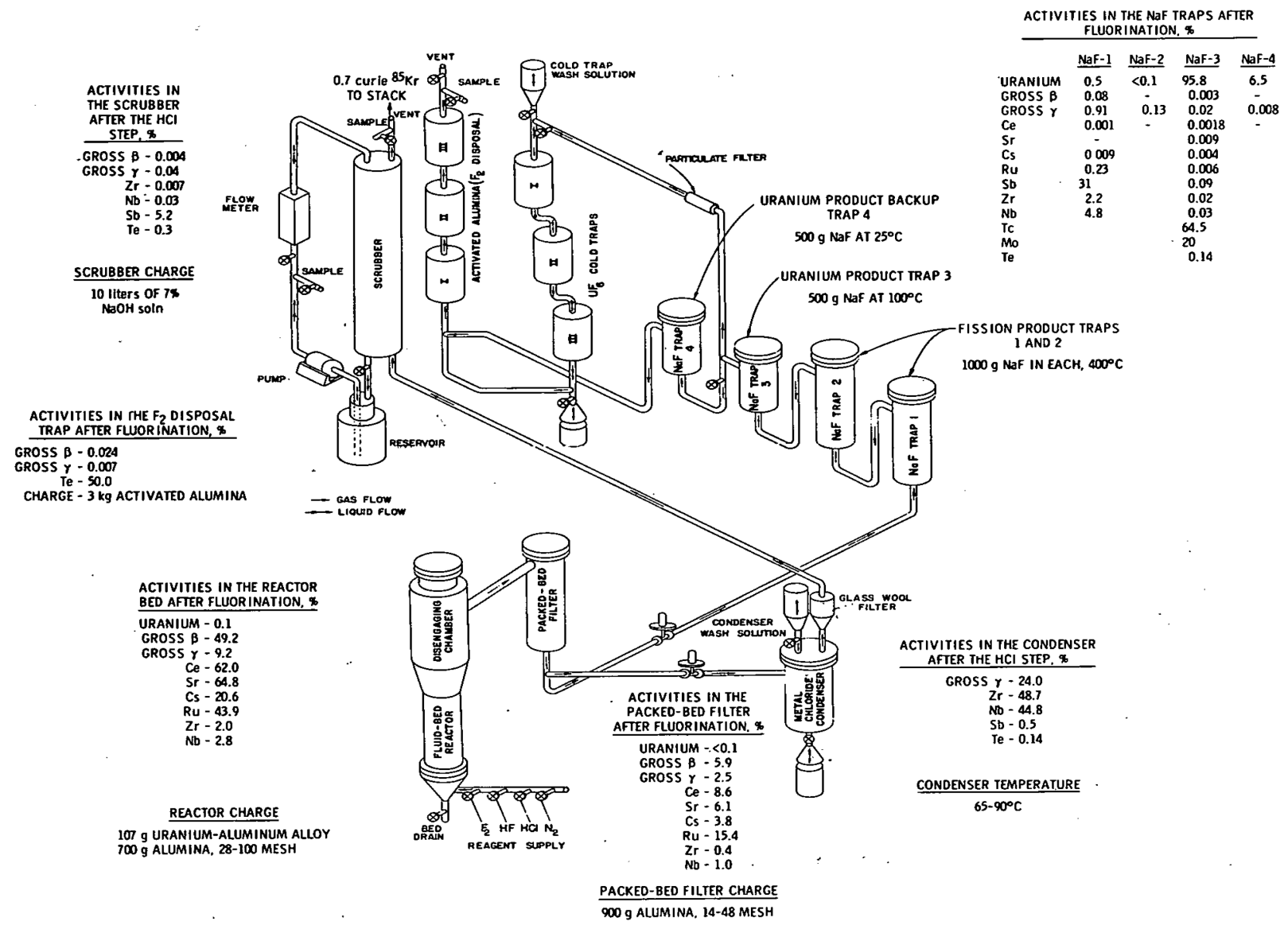

Figure A-4. Fluid-bed volatility processing of 7 month cooled U-Al alloy fuel-1st run.

In addition to $\mathrm{Mo}$, the fission products $\mathrm{I}, \mathrm{Kr}, \mathrm{Ru}, \mathrm{Sb}, \mathrm{Tc}$, and $\mathrm{Te}$ are volatilized at different times during these processes. The characteristic times and fission product volatilities for each process step are summarized in Table A-1.

Table A-1. Timetable for volatility processes used for aluminum-based fuel elements

\begin{tabular}{|l|l|c|l|}
\hline \multirow{2}{*}{ Process type } & \multicolumn{2}{|c|}{ Process step } & \multicolumn{2}{c|}{$\begin{array}{c}\text { Results for testing on aluminum research reactor } \\
\text { fuel element }\end{array}$} \\
\cline { 3 - 4 } & & Time (h) & \multicolumn{1}{c|}{ Fission product volatilized } \\
\hline Fluid bed & $300^{\circ} \mathrm{C} \mathrm{HCl} \mathrm{decladding}$ & $4-5$ & $\mathrm{Zr}, \mathrm{Nb}, \mathrm{Kr}, \mathrm{I}$ (slight: $\mathrm{Sb}, \mathrm{Te}, \mathrm{Tc})$ \\
\hline & $500^{\circ} \mathrm{C}$ Fluorination $\left(\mathrm{F}_{2}\right)$ & $\sim 4$ & $\mathrm{Mo}, \mathrm{Tc}, \mathrm{Te}$ \\
\hline Molten salt & $500^{\circ} \mathrm{C} \mathrm{HF}$ dissolution & $>12$ & $\mathrm{Sb}, \mathrm{Kr}($ partial: $\mathrm{Te}, \mathrm{I})$ \\
\hline & $500^{\circ} \mathrm{C}$ Fluorination $\left(\mathrm{F}_{2}\right)$ & $\sim 1.5$ & $\mathrm{Mo}, \mathrm{Tc}, \mathrm{Te}, \mathrm{I}, \mathrm{Nb}$ \\
\hline
\end{tabular}

These times for decladding and dissolution are rather long compared to the aqueous flowsheet and the equipment and reagents appear rather complex and unfamiliar to many. Although we expect excellent decontamination of ${ }^{99} \mathrm{Mo}$ on a temperature controlled network of $\mathrm{NaF}$ traps [A-8], the NaF desorption 
step and conversion to an acceptable aqueous product for generator manufacturers will require a time period that is yet to be defined, but we expect this step will not take more than 4 hours, although it may be just a few hours. The conversion to an aqueous solution could be as simple as cold trapping the $\mathrm{MoF}_{6}$ from NaF-trap desorption and adding water afterward, followed by elimination of the fluoride ion by the conventional sorption purification of molybdate on alumina.

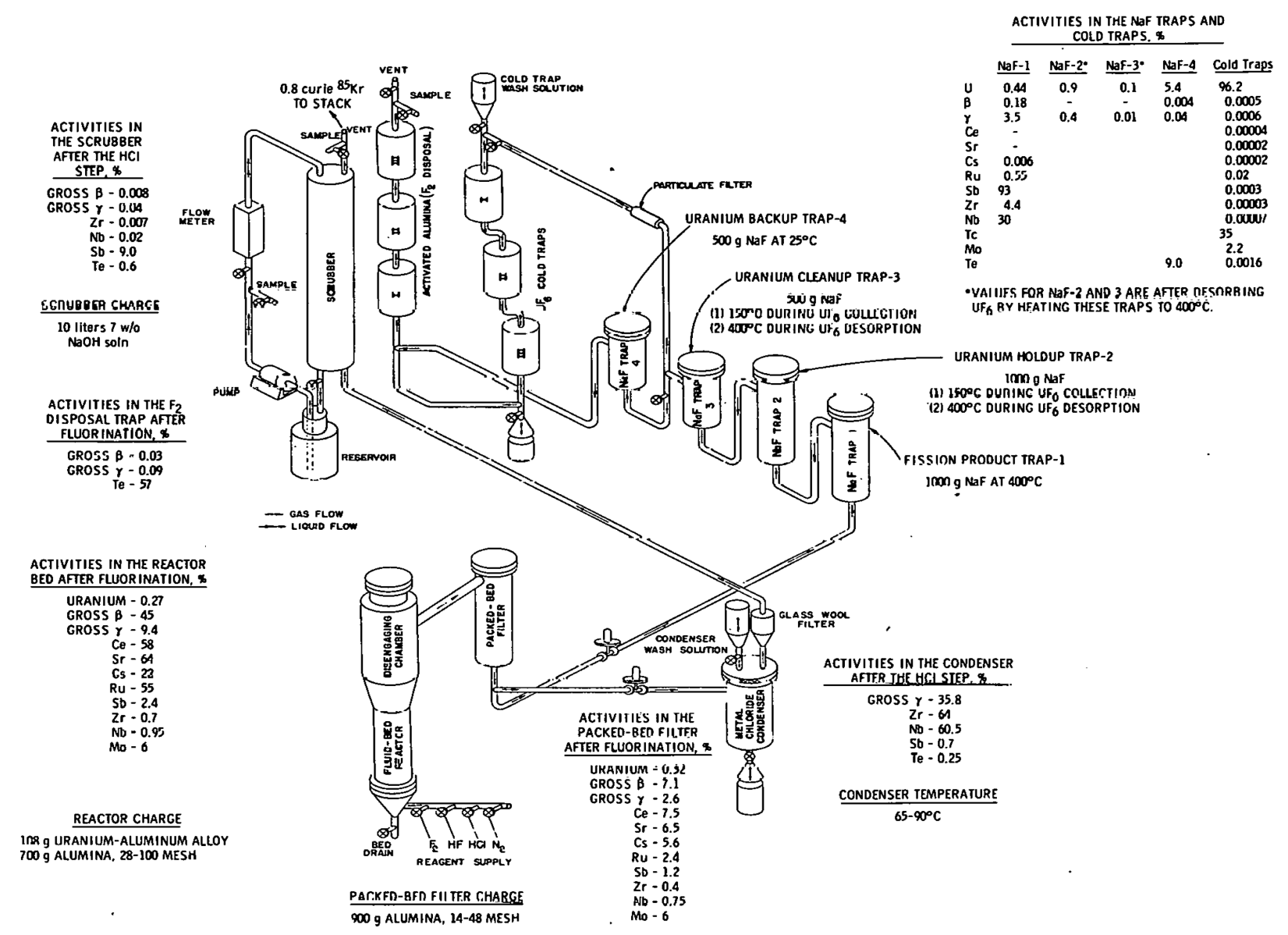

Figure A-5. Fluid-bed volatility processing of 7 month cooled U-Al alloy fuel-2nd run.

Likely, the steps outlined in Table A-1 will appear too slow compared to the established aqueous technology. Unless we can achieve a more rapid recovery of ${ }^{99} \mathrm{Mo}$, this pathway is unlikely to be attractive. The slow step is decladding, or in the case of molten salt process, fuel element dissolution. The fluorination step in a dry volatility process can be made just as rapid as the molten salt volatility step. To speed the decladding step, a different chemical reactor concept may be needed.

One way to speed the reaction in a controlled manner is to arrange for a reaction front that takes advantage of the excellent heat transfer properties of the ${ }^{99}$ Mo target. If the target wall is fixed to the interior reactor wall and adequate cooling at the external reactor wall is provided; the interior surface of the target can function as the decladding reaction front - as shown in the Figure A- 6 below for annular and flat plate geometries. A straightforward way to provide adequate cooling at low pressures while also stabilizing the reaction temperature is to immerse the reactor wall, or a portion of it, in a high-temperature bath (molten salt, fluid-bed, or liquid metal). 


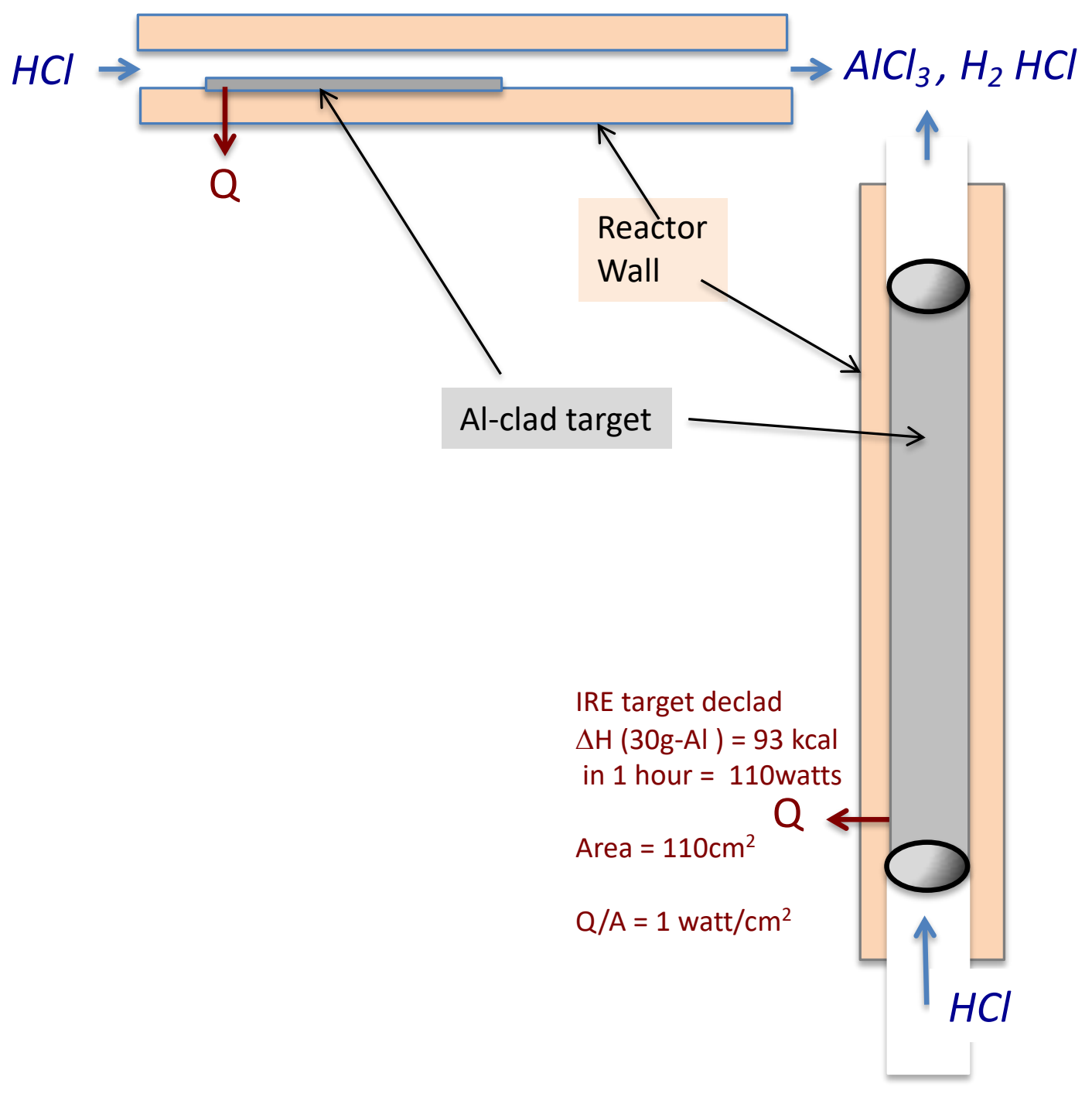

Figure A-6. Schematic heat transfer coupling to support halogenation reaction front.

\section{A-4. Application of volatility processes to new dense target matrices}

To increase production of ${ }^{99} \mathrm{Mo}$ without using highly enriched uranium, low-enriched uranium target matrices that have much higher uranium densities (g-U/cc-target-matrix) are proposed. Both low-enriched uranium silicide and metal matrices have been proposed and tested.

The silicide matrix is an approved research reactor fuel and looks very much like conventional aluminide fuel except that $\mathrm{U}_{3} \mathrm{Si}_{2}$ replaces the $\mathrm{UAl}_{\mathrm{x}}$ component. The silicide matrix has presented insurmountable difficulty for the existing aqueous processes for ${ }^{99}$ Mo recovery and has been abandoned because of this. The silicide matrix appears to present no such processing difficulty for the halide volatility approach. A recent South African study of the fluorination chemistry of $\mathrm{MoSi}_{2}$ confirms this [A-9]. The primary complication is that a significant quantity of $\mathrm{SiF}_{4}$ will need to be accounted for in the NaF trapping operation.

The metal foils developed by Argonne National Laboratory can also be efficiently processed by volatility methods, and in this case the decladding operation is simplified because it only amounts to removal of a thin $(15-40 \mu \mathrm{m})$ fission product barrier coating of $\mathrm{Al}$ or $\mathrm{Ni}$. The $\mathrm{Al}$ coating can be volatilized by $\mathrm{HCl}$, and 
the Ni coating can be removed by CO. The removal of these barrier coatings can be very rapid (matter of minutes). After this step, the uranium metal matrix can be directly fluorinated. After the barrier coating removal, a hydride/dehydride cycle could be employed to increase the surface area of uranium to speed fluorination, but this is probably not necessary.

Volatility flowsheets generate very little liquid waste. The primary chemical waste is radioactive $(\mathrm{Zr}, \mathrm{Nb})$ aluminum chloride that can be pyrohydrolized to aluminum oxide with some aluminum oxychloride content. The $\mathrm{HCl}$ from pyrohydrolysis can be recycled or dry trapped. The volatile fission product waste (I, Te, Sb, Tc) is contained on long-lived small-volume inorganic traps. The nonvolatile fission products exist in the ash from the chemical reactors and in the filter media used to retain particulates in the exhaust gases.

Low-burnup high-purity low-enriched uranium is recovered in volatility processing and can be directly recycled into the target making streams, instead of being stored as waste as is the current practice in most aqueous processing.

\section{A-5. Molten salt targets, fuels, and reactors for radioisotope production}

\section{Background on halide salts and processing options}

Molten fluoride nuclear fuels and coolants with melting points in excess of $300^{\circ} \mathrm{C}$

- $\quad$ sustain very high fission power densities $\left(8,000 \mathrm{w} / \mathrm{cm}^{3}\right)$ without undergoing radiation damage or exhibiting chemical instability except at temperatures below $150^{\circ} \mathrm{C}[\mathrm{A}-10]$ and

- exhibit favorable convective heat transfer performance (close to that of water) [A-11].

Previous studies indicate that radiolysis and heat transfer limits occur with frozen salts. At temperatures below $150^{\circ} \mathrm{C}$, solid fluorides are sensitive to ionizing radiation, and fluorine can be liberated from the solid leaving behind metal sites in the salt. Because solid fluorides exhibit a low thermal conductivity, their ability to transfer heat effectively is only realized when they become molten and natural and forced convection modes can contribute to thermal energy transport. Both of these factors highlight the need to maintain fluoride salts in the molten state during irradiation and above $150^{\circ} \mathrm{C}$ afterward when decay energy is accumulated in the salt. Fluoride nuclear fuel and coolants in the Aircraft Reactor Experiment and Molten Salt Reactor Experiment (MSRE) were maintained above their melting points during the entire life of these reactors (including dormant zero power periods), and radiolysis difficulties only arose years later during the storage of spent fuel salt at ambient temperatures after the reactors were shutdown. These same low-temperature salt radiolysis effects were seen decades earlier during exploratory capsule irradiations. A lesson from previous Oak Ridge National Laboratory experience is that irradiated fluoride salts must be maintained at temperatures above $150^{\circ} \mathrm{C}$ to avoid radiolysis.

For the employment of a fluoride salt matrix as the irradiation target for ${ }^{99}$ Mo production the chemical behavior of the fission generated Mo is of prime importance. Analysis of data from the operation of the MSRE and out-of-pile studies indicate that the Mo behavior is complex and that Mo does not remain dissolved in the salt but is in a reduced oxidation state and seeks other surfaces [A-12]. Metallic surfaces are reported to be preferred over graphite and gas-liquid interfaces, and it was postulated that gas-liquid surfaces served to concentrate and shuttle Mo before its final deposition. During MSRE operation the behavior of $\mathrm{Nb}$ was dependent upon the redox state of the salt [A-13], and thus we expect that Mo will be influenced by redox changes and by changes in the Lewis-acidity of the salt (the uncomplexed fluorideion concentration in the salt), which is known to effect the coordination bonding in molten salt systems. Out-of-pile studies also indicate that Mo does not exist as a dissolved fluoride in molten salt systems at 
redox conditions expected for molten salt fuels and targets [A-14 through A-27]. Oak Ridge National Laboratory reports indicate only extremely corrosive and oxidizing conditions could sustain moderate values (order of $100 \mathrm{ppm}$ ) of dissolved molybdenum fluorides and that intermediate oxidation states (II/IV) are unstable and disproportionate to metal and higher oxidation state species. This diversity of observations indicates that the disposition of Mo in fissioning molten salt systems is uncertain and was manifested in the MSRE by partitioning of fission product Mo to metal surfaces, graphite surfaces, and the gas-salt interface during reactor operation.

If fission molybdenum remains dispersed in the salt (even though not dissolved), then the salt could be withdrawn as a liquid and processed by the volatility approach described earlier. Just as ${ }^{99} \mathrm{Mo}$ in solid fuels can be dissolved in molten salt and fluorinated and removed as $\mathrm{MoF}_{6}$, the ${ }^{99} \mathrm{Mo}$ in molten salt targets can also be removed as $\mathrm{MoF}_{6}$ by direct fluorination with no need for dissolution or decladding.

If fission molybdenum distributes to the interior surfaces of the capsule, the entire capsule could be removed for volatility processing.

Another approach to processing is to promote a pathway to deposit molybdenum on a particular surface and then remove this surface for volatility processing - leaving the salt target in the reactor. Molybdenum-99 is preceded by the decay of zirconium-99 (2 seconds) and niobium-99 (15 seconds). Under most redox conditions $\mathrm{Zr}$ and $\mathrm{Nb}$ will dissolve in molten salt. As referenced previously, molybdenum will not dissolve in molten salt solution except under the most oxidizing conditions. Thus, it is the case that the parents of ${ }^{99}$ Mo dissolve into the molten salt and then decay to a specie that will not remain in solution (as happens in a number of families).

We can take advantage of the chemistry of the mass-99 fission chain by promoting the deposition of the $\mathrm{Nb}$ and Mo species from the molten salt. The collector surface (perhaps electrode) could then be removed and the salt left in the reactor. This approach would require maintaining the salt in a reduced state and would have the benefit of maintaining I, Te, Sb in salt solution. In addition to Mo and $\mathrm{Nb}$, it is likely other noble metal fission products such as $\mathrm{Ru}, \mathrm{Rh}, \mathrm{Pd}, \mathrm{Ag}$, and $\mathrm{Tc}$ would be co-deposited. The large majority of the mass of this deposit will be comprised of $\mathrm{Mo}, \mathrm{Nb}, \mathrm{Ru}$ and $\mathrm{Tc}$ - which all form volatile species during fluorination - thus processing this deposit should be straightforward. Because operation of the MSRE showed that Mo deposited primarily on metallic surfaces rather than graphite surfaces, we could make the capsule outer wall from low-surface area graphite and the inner removable collector (e.g., electrode) from an appropriate non-alloying metal. Should some of the uranium present co-deposit with the Mo - this would present no problem for halide volatility purification.

\section{Fluoride-salt irradiation-target concepts}

This approach covers the use of fluoride salt irradiation targets in both high-temperature gas-cooled and low-temperature water-cooled reactors.

The use of fluoride salts in high-temperature reactors (coolant temperature $>$ salt melting point) requires less specialized thermal design because the normal operating temperature of the reactor is above the melting point of the salt. Graphite-matrix coated-particle fuel can provide the fission energy not supplied by the target itself. In the absence of fission heat, auxiliary heaters maintain the salt in a molten state or restore it to the liquid state by progressive melting from the free surface. Salts can be introduced into and removed from the high-temperature target cavity in molten form by gravity-driven siphon or pressurized transfers through heated lines.

One concept for a high-temperature target would use the forced convection circulation technology developed for the MSRE. Another approach uses the natural convection properties of the fissioning salt 
target to provide adequate cooling with no provision for active pumping of radioactive salt outside the core.

The design of the fluoride salt target can be optimized to facilitate heat removal by natural convection. Above the mid-plane of the reactor, the target fission density decreases both axially and radially, and cooling should be supplied to the upper portion of the target. Below the mid-plane of the reactor, this same top-cooling bottom-heating geometry is repeated, but the salt cross section will be optimized to account for the peak neutron flux (and thus volumetric heat production) occurring at the top of target rather than at its bottom.

For a salt target in a high-temperature high-pressure reactor, the target boundary is cooled by pressurized $\mathrm{CO}_{2}$ or He gas and coupled to the gravity driven natural convection of the salt target itself. For the hightemperature low-pressure design, a low-pressure coolant such as another molten salt or a liquid metal is pumped or circulates by natural convection and is coupled to the molten salt target by its own natural convection.

The use of salt targets in low-temperature low-pressure water-cooled reactors will require careful thermal management (as done for other high-temperature specialized irradiation capsules) to maintain the salt in a molten state and remove heat from the target. Candidate salts for thermal spectrum reactor targets include a fissile fluoride $\left(\mathrm{UF}_{4}, \mathrm{PuF}_{3}\right)$ component dissolved in a solvent salt comprised of a combination of alkali fluorides, beryllium fluoride, zirconium tetrafluoride, and aluminum trifluoride, which form the following low-melting eutectics:

- Alkali-fluoride(s) mixtures (including enriched ${ }^{7} \mathrm{Li}$ )

- Alkali-fluoride $\mathrm{BeF}_{2}$ mixtures (including enriched ${ }^{7} \mathrm{Li}$ )

- Alkali-fluoride $\mathrm{ZrF}_{4}$ mixtures

- Mixtures of the previous two families with $\mathrm{AlF}_{3}$

Because the thermal margin of the salt is very high $\left(>1200^{\circ} \mathrm{C}\right.$ boiling point $)$ the limits on the dimensions of the target relate more to the container limits than the limits associated with the salt matrix. Containers made of Inconel, graphite, silicon carbide, alumina, and other refractory materials also have very high temperature limits, and the integrated thermomechanical design of each target design must be evaluated. As a starting point to see if salt targets are even feasible in water cooled reactors, Table 2 shows how much uranium could be loaded into the entire cylindrical volume of the Institute for Radioelements target [A-1] $(22 \mathrm{~mm}$ OD $\times 160 \mathrm{~mm}=61 \mathrm{cc}$ containing $4 \mathrm{~g}-\mathrm{U})$ for various candidate salts.

Table A-2. Uranium loading of salt within the 61 cc cylindrical envelope of the Institute for Radioelements target

\begin{tabular}{|c|c|c|c|}
\hline $\begin{array}{c}\text { Salt composition } \\
(\mathbf{m o l} \%)\end{array}$ & $\begin{array}{c}\text { Melting point } \\
\left({ }^{\circ} \mathbf{C}\right)\end{array}$ & $\begin{array}{c}\mathbf{6 0 0}^{\circ} \mathbf{C} \text { uranium conc. } \\
(\mathbf{g}-\mathbf{U} / \mathbf{c c})\end{array}$ & $\begin{array}{c}\text { grams of uranium } \\
\text { within 61 cc volume }\end{array}$ \\
\hline $\begin{array}{c}\mathrm{NaF}-\mathrm{BeF}_{2}-\mathrm{UF}_{4} \\
(57-42-1)\end{array}$ & 378 & 0.11 & 6.7 \\
\hline $\begin{array}{c}\mathrm{NaF}-\mathrm{BeF}_{2}-\mathrm{UF}_{4} \\
(73-17-10)\end{array}$ & 486 & 1.10 & 67 \\
\hline $\begin{array}{c}{ }^{2} \mathrm{LiF}_{4}-\mathrm{BeF}_{2}-\mathrm{UF}_{4} \\
(69-23-8)\end{array}$ & 426 & 1.04 & 63 \\
\hline $\begin{array}{c}\mathrm{NaF}-\mathrm{RbF}_{4}-\mathrm{UF}_{4} \\
(46-33-21)\end{array}$ & 470 & 1.69 & 103 \\
\hline
\end{tabular}


If the target irradiation hardware is redesigned, substantially more volume is likely available for salt irradiation than that associated with current targets geometries, so the numbers in Table 2 indicate that it may be possible to squeeze in a carefully designed salt target into existing irradiation envelopes.

\section{REFERENCES}

A-1. B. Ponsard, Medical Radioistopes Production in Research Reactors, presentation at 5th Symposium on Medical Radioisotopes: 2015-2020 Production and Transportation Challenges, Mol Belgium, 2015. https://science.sckcen.be/m/ /media/Files/Science/Events_2015/5thsymposium_05052015/1_B_P ONSARD.pdf?la=en

A-2. H. Aruno, Preparation of a Primary Target for the Production of Fission Products in a Nuclear Reactor, US Patent 3940318 A, February 24, 1976.

A-3. H. Aruno, Production of High Purity Fission Product Molybdenum-99, U.S. Patent 3799883 A, March 26, 1974.

A-4. L. Stein and R. G. Vogel, "Behavior of Uranium and Other Selected Materials in Fluorinating Reagents," Industrial and Engineering Chemistry (48), pp. 418-421, March 1956.

A-5. $\quad$ R. E. Leuze, Dry Fluoride Process Status Report, Oak Ridge National Laboratory, Report ORNL-980, 1951. https://www.osti.gov/src/fulltext/4328769

A-6. A. A. Jonke, "Reprocessing of Nuclear Reactor Fuels by Process based on Volatilization, Fractional Distillation, and Selective Adsorption," Atomic Energy Review (3), p. 5, 1965.

A-7. $\quad$ R. C. Vogel et al. Chemical Engineering Division Research Highlights: May 1965-April 1966. pp. 89-97, Argonne National Laboratory, Report ANL-7175, 1966. https://www.osti.gov/src/fulltext/4524994

A-8. A. A. Jonke, "Reprocessing of Nuclear Reactor Fuels by Process based on Volatilization, Fractional Distillation, and Selective Adsorption," Atomic Energy Review (3), pp. 46-49, 1965.

A-9. J. S. Gama et al., "A thermogravimetric study of the reactions of molybdenum disilicide with anhydrous hydrogen fluoride and fluorine," Journal of Fluorine Chemistry (145) pp. 66-69, January 2013.

A-10. L. M. Toth and L. K. Felker, "Fluorine generation by gamma radiolysis of a fluoride salt mixture," Radiation Effects and Defects in Solids, Vol. 112, pp. 201-210, 1990.

A-11. D. F. Williams, and K. T. Clarno, "Evaluation of Salt Coolants for Reactor Applications," Nuclear Technology (163), pp. 330-343, 2008.

A-12. W. R. Grimes, Radiation Chemistry of MSR System, Oak Ridge National Laboratory, Report ORNL-TM-500, p. 45, 1963. https://www.osti.gov/servlets/purl/12780864

A-13. R. J. Kedl, The Migration of a Class of Fission Products in the MSRE, Oak Ridge National Laboratory, Report ORNL-TM-3884, 1973. https://www.osti.gov/src/fulltext/4471292

A-14. E. L. Compere et al., Fission Product Behavior in the MSRE, Oak Ridge National Laboratory, Report ORNL-4865, p. 28, 1975. https://technicalreports.ornl.gov/1975/3445605698493.pdf

A-15. W. R. Grimes et al., Reactor Chemistry Division Annual Progress Report for Period Ending December 31, 1967. pp. 32-39, Oak Ridge National Laboratory, Report ORNL-4229. https://www.osti.gov/src/fulltext/4530360 
A-16. W. R. Grimes et al., Reactor Chemistry Division Annual Progress Report for Period Ending December 31, 1968, pp. 31-41, Oak Ridge National Laboratory, Report ORNL-4400, 1968. https://technicalreports.ornl.gov/1970/3445605155471.pdf

A-17. W. R. Grimes et al., Reactor Chemistry Division Annual Progress Report for Period Ending May 31, 1970, pp. 17-48, Oak Ridge National Laboratory, Report ORNL-4586, 1970. https://technicalreports.ornl.gov/1970/3445605703478.pdf

A-18. W. R. Grimes et al., Reactor Chemistry Division Annual Progress Report for Period Ending December 31, 1972, pp. 21-22 and 29, Oak Ridge National Laboratory, Report ORNL-4801, 1972. https://technicalreports.ornl.gov/1972/3445605154034.pdf

A-19. M. W. Rosenthal et al., Molten-Salt Reactor Program Semiannual Progress Report for Period Ending August 31, 1967, p. 142, Oak Ridge National Laboratory, Report ORNL-4191, 1967. https://www.osti.gov/src/fulltext/4497718

A-20. M. W. Rosenthal et al., Molten-Salt Reactor Program Semiannual Progress Report for Period Ending February 29, 1968. pp. 129-137, Oak Ridge National Laboratory, Report ORNL-4254, 1968. https://www.osti.gov/src/fulltext/4487235

A-21. M. W. Rosenthal et al., Molten-Salt Reactor Program Semiannual Progress Report for Period Ending August 31, 1968, pp. 150-155 and 170, Oak Ridge National Laboratory, Report ORNL4344, 1968. https://www.osti.gov/src/fulltext/4805939

A-22. M. W. Rosenthal et al., Molten-Salt Reactor Program Semiannual Progress Report for Period Ending February 28, 1969, pp. 157-159, Oak Ridge National Laboratory, Report ORNL-4396, 1969. https://www.osti.gov/servlets/purl/4785120

A-23. M. W. Rosenthal et al., Molten-Salt Reactor Program Semiannual Progress Report for Period Ending August 31, 1969, pp. 113-121, Oak Ridge National Laboratory, Report ORNL-4449, 1969. https://technicalreports.ornl.gov/1970/3445600500349.pdf

A-24. M. W. Rosenthal et al., Molten-Salt Reactor Program Semiannual Progress Report for Period Ending February 28, 1970, pp. 118 and 123-126, Oak Ridge National Laboratory, Report ORNL-4548, 1970. https://technicalreports.ornl.gov/1970/3445600500330.pdf

A-25. M. W. Rosenthal et al., Molten-Salt Reactor Program Semiannual Progress Report for Period Ending August 31, 1970, pp. 70-74, Oak Ridge National Laboratory, Report ORNL-4622, 1970. https://technicalreports.ornl.gov/1971/3445605157923.pdf

A-26. M. W. Rosenthal et al., Molten-Salt Reactor Program Semiannual Progress Report for Period Ending February 28, 1971, pp. 85-86, Oak Ridge National Laboratory, Report ORNL-4676, 1971. https://www.osti.gov/servlets/purl/4743040

A-27. M. W. Rosenthal et al., Molten-Salt Reactor Program Semiannual Progress Report for Period Ending August 31, 1971, p. 80, Oak Ridge National Laboratory, Report ORNL-4728, 1971. https://technicalreports.ornl.gov/1972/3445602851493.pdf 